\title{
Neuroinflammation and Modulation Role of Natural Products After Spinal Cord Injury
}

\section{Xue Wu \\ Yaping Yan \\ Qian Zhang}

National Engineering Laboratory for Resource Development of Endangered Crude Drugs in Northwest China, The Key Laboratory of Medicinal Resources and Natural Pharmaceutical Chemistry, The Ministry of Education, College of Life Sciences, Shaanxi Normal University, Xi'an, Shaanxi, The People's Republic of China
Correspondence: Qian Zhang

Email zhangqian 154@snnu.edu.cn

\begin{abstract}
Spinal cord injury (SCI) is a severe traumatic injury of the central nervous system, characterized by neurological dysfunction and locomotor disability. Although the underlying pathological mechanism of SCI is complex and remains unclear, the important role of neuroinflammation has been gradually unveiled in recent years. The inflammation process after SCI involves disruption of the blood-spinal cord barrier (BSCB), activation of gliocytes, infiltration of peripheral macrophages, and feedback loops between different cells. Thus, our first aim is to illustrate pathogenesis, related cells and factors of neuroinflammation after SCI in this review. Due to the good bioactivity of natural products derived from plants and medicinal herbs, these widely exist as food, health-care products and drugs in our lives. In the inflammation after SCI, multiple natural products exert satisfactory effects. Therefore, the second aim of this review is to sum up the effects and mechanisms of 25 natural compounds and 7 extracts derived from plants or medicinal herbs on neuroinflammation after SCI. Clarification of the SCI inflammation mechanism and a summary of the related natural products is helpful for in-depth research and drug development.
\end{abstract}

Keywords: spinal cord injury, neuroinflammation, blood-spinal cord barrier, microglia, astrocytes, natural products

\section{Introduction}

Spinal cord injury (SCI) is a severe traumatic injury of the central nervous system (CNS), characterized by a high disability and lethality rate. It always takes a heavy burden to families and society. With rapid development of economies, SCI incidence is steadily on the increase year by year. SCI may be induced by traffic accidents, falls, violence and so forth. When an injury happens, an instantaneous or continuous force is exerted, leading to fracture or shift of the spine and compression or breaking of the spinal cord. Then, a delayed secondary injury follows, which involves complicated physiological and biochemical cascade reactions. Many important events occur in this stage at the lesion site, including hematoma, edema, neuroinflammation, as well as extensive death of neurons and gliocytes. ${ }^{1}$ Meanwhile, extent and degree of injury continuously extends, resulting in neurological and locomotor dysfunction. ${ }^{2}$

Significance of neuroinflammation in the diseases related to injured CNS is undoubted, such as Alzheimer's disease, Parkinson's disease and multiple sclerosis. ${ }^{3}$ In recent years, attention on neuroinflammation in SCI is increasing. Pathological processes of neuroinflammation after SCI include blood-spinal cord barrier (BSCB) destruction, infiltration of leukocytes to spinal cord parenchyma, 
activation of gliocytes at lesion site, secretion of cytokines and chemokines, as well as the consequent vicious circle. Both beneficial and detrimental effects have been reported previously, so the role of neuroinflammation is controversial. ${ }^{4}$ Thus, the first aim of this review is to illustrate pathogenesis, related cells and factors of neuroinflammation after SCI.

Application of natural products has been a hotspot in the field of SCI research in recent years. Natural products are usually derived from plants and medicinal herbs. Because of their source, natural products are easy to accept and have widely existed in our lives in the form of healthcare products or drugs for long time. Effects and mechanism of natural products targeting neuroinflammation in various CNS diseases have been reported, including SCI. ${ }^{5,6}$ Therefore, the second aim of this review is to sum up the effects and mechanisms of natural ingredients and extracts derived from plants or medicinal herbs on neuroinflammation after SCI in detail.

\section{Pathogenesis of Neuroinflammation After SCI}

With regard to inflammatory response, the responding area of inflammatory response is mainly restricted within the injured spinal cord, which is also referred to as a local inflammatory microenvironment. SCI also can trigger systemic inflammatory response syndrome, which affects multiple distal organs and is a threat to life. ${ }^{2}$ The three most important steps are discussed as follows.

\section{Disruption of BSCB}

As a specific protective barrier, BSCB helps to maintain homeostasis by blocking entry of pathogens, bloodderived cells and products into spinal cord parenchyma. BSCB is composed of endothelial cells, pericytes, astrocytes and basal lamina at the cellular level (Figure 1), which is analogous to the blood-brain barrier (BBB). However, some characteristics in structures distinguish BSCB from BBB. First, capillaries of BSCB are unaffected by histamine, 5-hydroxytryptamine and noradrenaline, because of a lack of contractile proteins. Second, there are insufficient pinocytosis vesicles in endothelial cells of BSCB, which restricts the ability of transporting macromolecules. Third, microvessels of the spinal cord possess glycogen deposits, which are not normally seen in cerebral vasculature. Lastly, BSCB processes have increased permeability compared with $\mathrm{BBB}$, which might be explained by lower expressions of transporter molecular (P-glycoprotein), tight junction (TJ) and adherens junction (AJ) proteins (ZO-1, occludin, VE-cadherin, $\beta$ catenin) in endothelial cells ${ }^{7,8}$ (Figure 2).

Structural damage of BSCB happens almost at the moment of SCI. Verified by magnetic resonance imaging analyses, time range of BSCB dysfunction occurs within 5 minutes, and lasts up to 28 days after SCI. In some reports, this period could last as long as 56 days. ${ }^{9}$ After SCI, perivascular basal lamina is separated; vesicular transport across capillary endothelium is increased; and TJs between endothelial cells are widened. These increased channels directly lead to the increase of BSCB permeability. Thus,

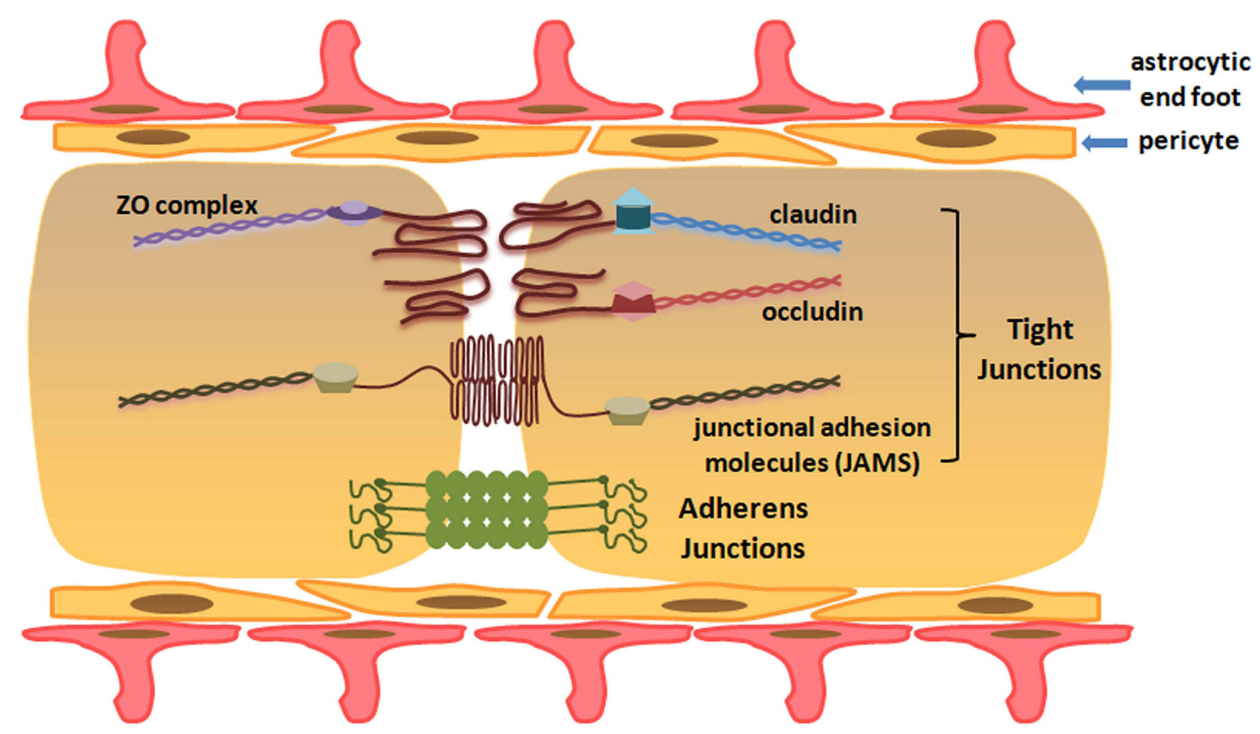

Figure I Cellular and molecular structure of blood-spinal cord barrier. 


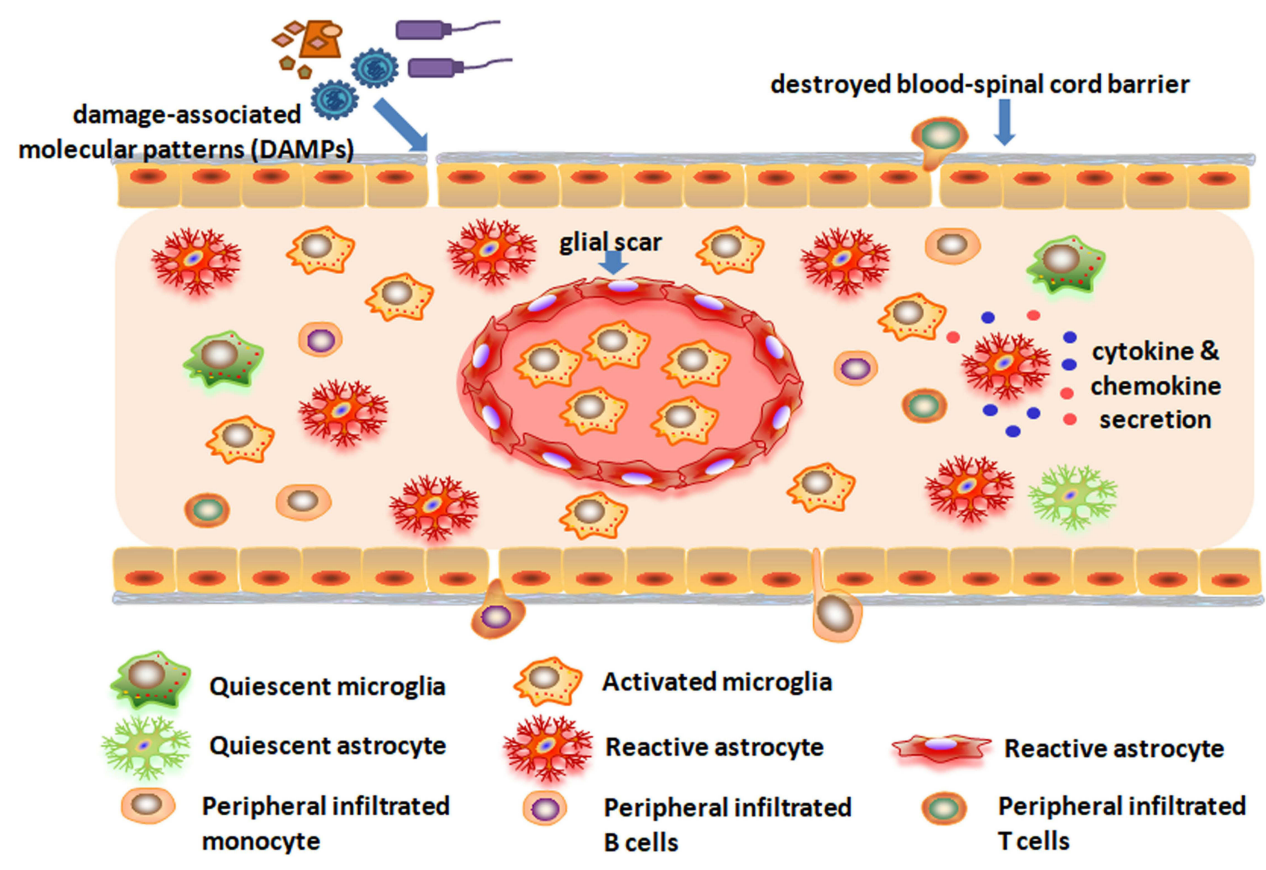

Figure 2 Activation of gliacytes and infiltration of peripheral immune cells after spinal cord injury.

excess water, ions, inflammatory factors, immune cells (neutrophils, lymphocytes, etc.) and foreign substances infiltrate into spinal cord parenchyma. ${ }^{10}$ Many factors are also involved in this process, including matrix metalloproteinases (MMPs), heme oxygenase (HO), angiopoietin (Ang), aquaporin-4 (AQP-4) and caveolae-1 (Cav-1). ${ }^{8}$

As extracellular zinc and calcium-dependent endopeptidases, MMPs could degrade TJs proteins, extracellular matrix (fibronectin, laminin, heparin sulfate, etc.) and surrounding basal lamina, which promotes wound healing. However, excessive proteolytic activity of MMPs could destroy BBB/BSCB after injury. ${ }^{11}$ After SCI, both beneficial and detrimental effects of MMPs have been proved. MMP-2 is conducive to wound healing and functional recovery after SCI. ${ }^{12}$ Whereas, MMP-3, MMP-9 and MMP-12 promote BSCB disruption, inflammation, and development of secondary injury. For instance, in SCI mice with a genetic null mutation in MMP-3, MMP-9 or MMP-12, better BSCB restoration, lower densities of microglia and macrophages are observed, compared with wild-type mice. ${ }^{13}$ MMP-9 is involved in abnormal vascular permeability and inflammation within the first 3 days after SCI. ${ }^{14}$ MMP-12 is critical for the migration of bloodborne macrophages across endothelial basal lamina into inflammatory sites. ${ }^{15}$

$\mathrm{HO}$ is a rate-limited enzyme which catalyzes heme, effectively degrading into equimolar quantities of biliverdin, carbon monoxide and $\mathrm{Fe}^{3+}$. Among the three reported isoenzymes (HO-1, 2, 3), HO-1 and HO-2 have been verified in their effectiveness in defending CNS injury. After SCI, HO-1 prevents further damage by controlling death of injured cells via an intrinsic suicide program; while HO-2 inhibits inflammatory responses induced by NO-derived radicals. ${ }^{16,17}$ Besides, HO-1 could stabilize the BSCB, by increasing expression in activated neutrophils, and regulation of interleukin (IL)10 and tumor necrosis factor- $\alpha(\mathrm{TNF}-\alpha)$ level. ${ }^{18,19}$

As vascular growth factors, angiopoietins contribute to blood vessel formation/maturation, endothelial cell survival, and normal vascular functions in brain and spinal cord. Among the Ang family (Ang1-4), Ang-1 and Ang2 function as ligands for the endothelial-specific receptor tyrosine kinase, Tie- $2 .^{20}$ Ang-1 reduces endothelial permeability of noncerebral vessels, having beneficial effects as vascular and inflammatory regulators in vascular stabilization and maturation. Conversely, Ang-2 is thought to be an endogenous antagonist of the action of Ang-1 at Tie-2 after CNS injury. ${ }^{21,22}$

As the most abundant isoform in CNS, the water channel protein AQP-4 is mainly distributed in endothelial cells and astrocytes. It mediates water flux across $\mathrm{BBB} / \mathrm{BSCB}$, thus increasing the water content and destroying the $\mathrm{BBB} / \mathrm{BSCB}$ stabilization. ${ }^{23,24}$ AQP-4 gene knockout rats showed alleviated spinal cord edema, and better recovery in sensory 
and motor function after SCI. ${ }^{25}$ Recent studies showed that calmodulin directly binds to the AQP4 carboxyl terminus, causing a specific conformational change and driving AQP4 cell-surface localization. Inhibition of calmodulin in a rat spinal cord injury model could alleviate CNS edema, and lead to accelerated functional recovery. ${ }^{26}$

Caveolae is a series of vesicles participating in endocytosis and exocytosis of endothelial cells, which regulate substance transportation between inside and outside of vessels. Three isoforms have been reported (Cav-1, 2, 3), and Cav-1 is the main form. Cav-1 distributes in CNS in low abundance, inducing reduction of endocytosis-exocytosis ratio and low permeability of blood-CNS barrier. After SCI, Cav-1 expression increased and induced neuronal regeneration at lesion rostral side. ${ }^{27}$ Besides, Cav-1 phosphorylation was markedly enhanced in inflammatory macrophages, activated microglia and endothelial cells in the injured spinal cords, which was accompanied by adding edema soon. ${ }^{28}$ Endothelial cells permeability in rats with Cav-1 gene knockdown via siRNA also significantly increased, which verified that Cav-1 is crucial in hyperpermeability of BSCB disruption after SCI. ${ }^{29}$

\section{Cell Death and Pattern Recognition Receptors}

Accompanied with the BSCB disruption, blood-borne molecules and cells cross BSCB easily and infiltrate into the injured parenchyma, triggering further spinal cord damage. According to previous research, the first wave of cell death occurs in the acute stage of SCI (within 3 days after injury), which mainly involves neurons and gliacytes. The types of cell death programs include apoptosis, necroptosis and pyroptosis. No matter which kinds of cell death programs, they participate in host defense through injured cells, and are regulated by signals derived from pattern recognition receptors (PRRs).

PRRs are highly conserved across multiple species, acting as one of the first defensive lines against pathogens and foreign materials. ${ }^{30}$ Broadly expressed in different types of cells in CNS, several sub-families of PRRs have been identified, including Toll-like receptors (TLRs), Nod-like receptors (NLRs), C type lectin receptors (CLRs) and RIG-like receptors (RLRs). PRRs are capable of recognizing pathogens (pathogen-associated molecular patterns-PAMPs) and molecules (damage associated molecular patterns-DAMPs). DAMPs refer to cellular debris of dead cells and intracellular constituents released by injured cells, including proteins (e.g., hemoglobin and its products), purine metabolites (e.g., ATP), RNA, and DNA. During tissue stress or damage, DAMPs are potent immunogens and activate PRRs on the innate immune cells, then inducing co-stimulatory signals for the adaptive immune cells and stimulating an inflammatory response. Their final aim is to eliminate infectious agents and induce death of infected cells. In another words, PRRs equip our body to distinguish "healthy" or tissue homeostasis from "potential danger" or tissue damage. ${ }^{31}$

Till now, three TLRs (TLR2, TLR4, TLR9) and two RLRs (Rig1, MDA5) have been studied in preclinical models of SCI. Contribution of TLR9 to SCI was studied by intrathecal injection (i.t.) of TLR9 antagonist (cytidinephosphate-guanosine oligodeoxynucleotide 2088, CpG ODN2088) and agonist (CpG ODN 1826) in mice. CpG ODN2088 could decrease the number of CD11b-, CD45and CD3-immunoreactive cells and reduce TNF- $\alpha$ expression at the epicenter 2 weeks after injury. Opposite results were observed after administration of CpG ODN $1826 .{ }^{32}$ SCI also significantly induced TLR2, TLR4, CD14, MyD88, and I IKB- $\alpha$ mRNA expression at the lesion. Accordingly, TLR4 mRNA is significantly induced in activated microglia in and around the lesion, while TLR2 is upregulated on both microglia and astrocytes 2 weeks postinjury. Compared with SCI wild-type mice, SCI TLR4 mutant $(\mathrm{C} 3 \mathrm{H} / \mathrm{HeJ})$ and TLR2 knockout $\left(\mathrm{TLR}^{-/-}\right)$mice exhibited impaired locomotor function and severe neuroinflammation, which evidenced the significance of TLR2 and TLR4 signaling in vivo. ${ }^{33}$ After SCI, short nucleic acids, a signature of damaged cells, were sensed intracellularly by RIG11 and MDA5 in astrocytes. Then, astrocytes were activated accompanied with increasing glial fibrillary acidic protein (GFAP) and vimentin, which induced RLR signaling activation and neuroinflammation. ${ }^{34}$ Activation of these PRRs leads to production of inflammatory mediators and activation of resident inflammatory cells in spinal cord parenchyma, which help remove pathogens or restore tissue homeostasis (Figure 2). ${ }^{35}$

\section{Activation of Gliocytes in Spinal Cord}

Gliocytes refer to the non-neuronal cell types which reside in nervous system, including astrocytes, microglia, oligodendrocytes and their progenitors. In CNS, oligodendrocytes are specialized to maintain effective axon conduction through myelination and trophic support. According to present reports, they are barely concerned in neuroinflammation research. So, we just discuss microglia and astrocytes in this review. 


\section{Microglia}

Microglia are the main resident immune cell in CNS, and constitute $20-40 \%$ of all CNS cells in mammals. Besides their immunocompetence, microglia also could remove synapses and refine circuits to modulate synaptic activity, ${ }^{36}$ produce trophic factors to support neuron survival and axon growth, ${ }^{37}$ and assist survival and myelination of oligodendrocyte precursor. ${ }^{38}$ In this review, we focus on their roles in neuroinflammation after SCI.

As the resident innate immune cells in CNS parenchyma, microglia express all known members of TLRs, and constitutively express TLR2. ${ }^{39}$ After trauma, massive upregulation of DAMPs and cytokines induce microglia activation by binding to PRRs or other cell surface receptors. Morphological change is different according to injury degree. Moderately activated microglia show hypertrophic morphology with shorter processes, while strongly activated microglia take on an amoeboid morphology. ${ }^{40}$ They show strong inflammatory response and increase in proliferation, as well as migration from perilesional zone to the lesion epicenter.

In addition, hematogenous macrophages and polymorphonuclear leukocytes (PMNs) are attracted by chemotactic factors, pass through the disruptive $\mathrm{BSCB}$, and infiltrate into the lesion site of the spinal cord. These recruited macrophages, infiltrated PMNs and migrated microglia gather in and around the lesion epicenter, remaining detectable till the chronic phase (180 days after SCI) ${ }^{41}$ It is difficult to distinguish the hyperactivated microglia from hematogenous macrophages in the lesion site. So, they are usually referred to as microglia/macrophages. The classical/pro-inflammatory (M1) and alternative/anti-inflammatory (M2) classification is broadly applied in macrophages. It is also applied to functional status of microglia/macrophages after $\mathrm{SCI} .{ }^{42,43}$ To a great extent, the ratio of M1 and $\mathrm{M} 2$ phenotype determines the inflammatory microenvironment at lesion site. In healthy condition, M1/M2 phenotype of microglia/macrophages located in spinal cord parenchyma display a balance. After trauma, M1 phenotype occupies a predominant state within 28 days post-injury, ${ }^{42}$ resulting in high production of proinflammatory cytokines, such as TNF- $\alpha$, IL-1, IL-6, IL-12, IL-23, IL-1 $\beta$, interferon- $\gamma$ (IFN- $\gamma$ ) and inducible nitric oxide synthase (iNOS). ${ }^{43,44}$ These cells and molecules collectively create the inflammatory microenvironment at the lesion site, which is unfavorable for polarization towards M2 phenotype. In a study by Kigerl et al., when in vitrotransformed M2 phenotype microglia/macrophages (EGFP
+ ) were injected into lesion site of spinal cord, $20-40 \%$ of them rapidly switched to M1 phenotype. ${ }^{42}$

\section{Astrocytes}

As the most abundant glial cells, astrocytes are traditionally viewed as supportive and nutritive cells for neurons, and each astrocyte contacts 300-600 neuronal dendrites. ${ }^{45}$ Its main functions include neuronal guidance (development, migration and differentiation), ${ }^{46}$ synapse formation, ${ }^{47}$ BBB/BSCB construction, ${ }^{48}$ modulation of blood flow, ${ }^{49}$ storage site of glycogen in $\mathrm{CNS},{ }^{50}$ as well as regulation of extracellular balance of ions, fluid and neurotransmitters. ${ }^{51}$ It's worth noting that growing evidence supports an essential role of astrocytes in central immunity, which is discussed in this review.

When damage occurs in brain and spinal cord, astrocytes are activated by inflammatory signals and DAMPs. The former one refers to neurosignals, cytokines and chemokines secreted by other cells in CNS. The latter one, DAMPs, has already been described above. ${ }^{51}$ The most studied PRRs in astrocytes are TLRs. Compared with microglia, astrocytes express more limited TLRs, and TLR3 expression has reached a consensus in cultured human and murine astrocytes. ${ }^{52,53}$ Astrocytes are also reported to express TLR $1,4,5,7,8$ and $9 ;{ }^{39}$ however, this is still controversial and more evidence is needed.

After activation, the typical response of astrocytes in CNS is astrogliosis. Minor astrogliosis includes astrocytic hypertrophy and changes in related gene expression. Severe astrogliosis includes cellular proliferation, tissue rearrangement and glial scars formation. ${ }^{54}$ A series of inflammatory factors and chemokines are released by activated astrocytes, which initiate and regulate the subsequent immune response. The inflammatory factors include TNF- $\alpha$, TGF$\beta$, IL-1 $\beta$, IL-4, IL-6, IL-9, IL-10, IL-11, IL-12, IL-15, IL17, IL-23, IL-27, IFN- $\alpha$, IFN- $\beta$ and iNOS. The chemokines include CCL2, CCL3, CCL4, CCL5, CCL7, CCL20, CXCL1, CXCL2, CXCL3, CXCL6, CXCL8, CXCL9, CXCL10 and CXCL12. ${ }^{51}$ By releasing these inflammatory signals, astrocytes exert immunological functions after CNS damage, including SCI.

First, the released inflammatory signals collectively regulate expression of adhesion molecules in BBB/ $\mathrm{BSCB}$, such as intercellular cell adhesion molecule (ICAM)-1 and vascular cell adhesion molecule (VCAM)-1. ${ }^{55,56}$

Second, upregulation of astrocytic chemokines expression in and around the lesion site directly attracts lymphocytes infiltration and monocyte/microglia migration. 
Lipopolysaccharide (LPS, TLR4 ligand) induces increased expression of CXCL10 in astrocytes, then attracting Th1 lymphocytes. ${ }^{57}$ After stimulation with poly (I:C) (TLR3 ligand), astrocytes increasingly express CXCL10 and CCL5, attracting CCR5+ Th1 cells, CD8+ cells and NK cells. ${ }^{58}$ Following treatment with high-mobility group box 1 protein (HMGB1), expressions of TNF- $\alpha$, CCL5, CCL2, CCL3, CCL20, CXCL1, CXCL2 and CX3CL1 in primary rat astrocytes significantly increased, encouraging migration of monocyte/microglia. ${ }^{59}$ These observations are also supported by in vivo studies, for example, in situ hybridization of brain and spinal cord of mice with inflammation. ${ }^{60}$

Third, besides the innate immune system, astrocytes also modulate adaptive immune responses in CNS. It could release inflammatory signals (IFN- $\gamma$, IL-12, IL-10) to regulate T-cell differentiation and Th1/Th2 balance in neuroinflammation. ${ }^{61} \mathrm{~A}$ recent study suggests that astrocytes also could act as antigen-presenting cells and activate T-cells in brain in Parkinson's disease. ${ }^{62}$

Different from microglia, investigation about astrocytes classification started as late as $2012 .{ }^{63}$ By analogy with M1 and M2 macrophages/microglia, two phenotypes of reactive astrocytes are defined as A1 and A2. ${ }^{64,65} \mathrm{~A} 1$ astrocytes possess a neurotoxic effect and participate in the pathogenesis of multiple neurologic diseases. In contrast, A2 astrocytes are suggested to display a neuroprotective effect. ${ }^{62,66,67}$ Only a few studies focus on effects of astrocytic polarization on neuroinflammation in CNS diseases, such as acute cerebral ischemia and SCI. ${ }^{68,69}$ Phenotype and functions of astrocytic polarization will gradually show importance in neuroinflammation in CNS over the next few years.

\section{Glial Cell Interactions to Shape}

\section{Neuroinflammation}

After activation of microglia and astrocytes, cell-cell interactions are also critical to shape inflammatory microenvironment, then influence neurons and oligodendrocytes after SCI. ${ }^{40}$ Cross-talk between activated gliocytes could form feed-forward loops to amplify the detrimental or beneficial effect. For example, compared with microglia alone, microglia cultured with astrocytes secrete increasing proinflammatory factors after stimulating with LPS. ${ }^{70}$

Although microglia and astrocytes constitute an inflammatory microenvironment together, the inflammatory response of microglia is much stronger than astrocytes. The activated microglia could strongly influence the phenotype and responses of astrocytes. In a recent study, IL- $1 \alpha$, TNF and
$\mathrm{C} 1 \mathrm{q}$ are identified as the key factors secreted by microglia. These cytokines are upregulated and cooperate to induce A1 astrocytes, causing death of neuronal and oligodendrocytes. ${ }^{71}$ Microglia also secrete excessive TNF- $\alpha$ and upregulate prostaglandin E2 in astrocytes, eliciting increasingly release of glutamate and excitotoxicity ultimately. ${ }^{72,73}$ Besides, IL-10 produced by microglia act on astrocytic IL-10R1 receptors, and stimulate production of TGF $\beta$. In turn, the secreted TGF $\beta$ could attenuate microglial activation. ${ }^{74}$

Of course, astrocyte-derived inflammatory mediators also exert an influence on microglia. Galectin- 9 secreted by astrocytes could promote secretion of TNF by microglia. ${ }^{75}$ Besides, astrocytes are reported to release complement $\mathrm{C} 3$ after activation of nuclear factor kappa $\mathrm{B}(\mathrm{NF}-\mathrm{\kappa B})$. On one hand, $\mathrm{C} 3 \mathrm{a}$ acts on neuronal $\mathrm{C} 3 \mathrm{a}$ receptor $(\mathrm{C} 3 \mathrm{aR})$, promoting axon growth and neuron survival after $\mathrm{SCI} .{ }^{76}$ On the other hand, it acts on microglial $\mathrm{C} 3 \mathrm{aR}$, which promotes microglial phagocytosis in acute neuroinflammation and attenuates microglial phagocytosis in chronic neuroinflammation. ${ }^{77}$ In a study by Hung et al., expression of astrocytic growth-associated protein 43 (GAP43) significantly increases induced by LPS, and regulated by TLR4/NF- $\kappa$ B/STAT3 axis activation. Astrocyte-conditioned media from GAP43 knock-down astrocytes could attenuate microglial activation and proinflammatory cytokines expressions. ${ }^{78}$ In addition, astrocytes could also decrease microglial adhesion and costimulatory molecule expression. ${ }^{79}$

To sum up, complicated crosstalk between astrocytes and microglia has been gradually unveiled in recent years. Positive or negative feedback loops between different types of gliocytes, as well as gliocytes and neurons, lead to sophisticated regulation and mechanisms, which are crucial for homeostasis of CNS. Especially in the pathological process of neuroinflammation, disentanglement of these gliocytes' interaction is a slow and arduous task, but crucial and necessary for study of the mechanism of SCI.

\section{Modulatory Effects of Natural Compounds on Neuroinflammation After SCI \\ Natural Compounds Targeting BSCB After $\mathrm{SCl}$}

Salvianolic acid A is a water-soluble phenolic acid isolated from dried rhizome and root of Chinese sage (Salvia miltiorrhiza Bge.). In clinical practice, salvianolic acid A has been applied for treating dozens of diseases, including 
cardiovascular disease, ${ }^{80}$ cerebrovascular disease, ${ }^{81}$ hepatic fibrosis, ${ }^{82}$ and diabetes mellitus. ${ }^{83}$ Its therapeutic effects on BSCB restoration after SCI have been investigated in recent years. In research of Yu et al., salvianolic acid $\mathrm{A}(5,10 \mathrm{mg} / \mathrm{kg} / \mathrm{day}$, intraperitoneal injection (i.p.) for 7 days) could reverse decrease of BSCB permeability, evaluated by EB content in damaged spinal cord tissue of SCI rats. It also significantly increased expressions of HO-1 and TJ proteins (ZO-1, claudin-5), while decreasing p-Cav-1 expression, compared with control group. Its effect could be suppressed by HO-1 inhibitor, zinc protoporphyrin (ZnPP) IX. In a hypoxia model of rat brain microvascular endothelial cells (RBMECs), salvianolic acid A $(20,100 \mu \mathrm{mol} / \mathrm{L}, 24$ hours $)$ could significantly increase HO-1 and transendothelial electric resistance, thus decreasing RBMECs permeability. Effects of salvianolic acid A on BSCB restoration are associated with suppression of miR-101/Cul3/Nrf2/HO-1 signaling pathway. ${ }^{84}$

Salvianolic acid B is another water-soluble phenolic acid isolated from dried rhizome and root of Chinese sage (Salvia miltiorrhiza Bge.), and has similar chemical structure and pharmacological actions with salvianolic acid A. ${ }^{85,86}$ In Fan's research, consecutive administration of salvianolic acid B $(10,50 \mathrm{mg} / \mathrm{kg} / \mathrm{day}$, i.p.) significantly decreased BSCB permeability and spinal cord tissue water content, as well as increasing levels of TJ proteins (ZO-1, occludin) and HO-1 in spinal cord at 12, 24, 48 and 72 hours after SCI. This effect could be suppressed by the HO-1 inhibitor ZnPP. ${ }^{87}$ Its mechanism is associated with activation of extracellular signal-regulated kinase (ERK) and mitogen-activated protein kinase (MAPK) pathways. ${ }^{88}$

Protocatechuic acid (3, 4-dihydroxybenzoic acid) is a phenolic acid compound which is widely present in edible plants, common herbs and Traditional Chinese Medicine, including olives (Olea europaea Linn.), onion (Allium cepa L.), white grapes (Vitis vinifera L.), rosemary (Rosmarinus officinalis Linn.), cinnamon (Cinnamomum aromaticum Nees), Chinese sage (Salvia miltiorrhiza Bge.), ginkgo (Ginkgo biloba L.), sharp-leaf galangal (Alpinia oxyphylla Miq.). ${ }^{89}$ In Park's study, after consecutive administration of protocatechuic acid $(50 \mathrm{mg} / \mathrm{kg} / \mathrm{day}$, i.p. for 7 days), the trend of increase of EB extravasation and hemorrhage in spinal cord tissue was significantly reversed. Meanwhile, increase of TJ proteins (ZO-1, occludin) expression and decrease of MMP-9 level were particularly prominent in the protocatechuic acid group. ${ }^{90}$

\section{Natural Compounds Targeting Gliacytes After SCl}

Tetramethylpyrazine, also named ligustrazine, is an alkaloid compound extracted from Chuanxiong Rhizoma, which is the dried rhizome of Ligusticum chuanxiong Hort. in Umbelliferae. Previous studies show that tetramethylpyrazine exhibits satisfactory effect in treating SCI through attenuating inflammation. Tetramethylpyrazine treatment $(200 \mathrm{mg} / \mathrm{kg} /$ day, i.p. for 5 days; $15,30 \mathrm{mg} / \mathrm{kg}$, i.p., 30 minutes before $\mathrm{SCI}$ ) could significantly inhibit proteins and mRNA expressions of NF- $\mathrm{KB}$, cyclooxygenase-2 (COX-2) and pro-inflammatory factors (TNF- $\alpha$, IL$1 \beta$, IL-18, macrophage migration inhibitory factor), while increasing proteins and mRNA expressions of anti-inflammatory factors (IL-10) in spinal tissues. ${ }^{91-94}$ Tetramethylpyrazine also attenuated neutrophil infiltration by suppressing the increase of P-selectin expression and myeloperoxidase (MPO) positive neutrophils within 14 days post-SCI. ${ }^{91,94}$ These changes may be related to microglial polarization from M1 phenotype to M2 phenotype modulated by tetramethylpyrazine, while activation of STAT3/SOCS3 pathway and inhibition of NF- $\mathrm{KB}$ pathway were involved. ${ }^{95}$

Polydatin, also known as piceid, mainly exists in dry rhizome and root of Polygonum cuspidatum Sieb. et Zucc. It has promising anti-inflammatory and anti-oxidant effects. ${ }^{96}$ In SCI rats, single polydatin administration (20, $40 \mathrm{mg} / \mathrm{kg}$, i.p.) remarkably decreased levels of NO, $1 \mathrm{~L}-1 \beta$, IL-6 and TNF- $\alpha$ in spinal tissue. In BV-2 microglial cells treated with LPS, polydatin treatment $(1,2,4 \mu \mathrm{mol} / \mathrm{L}, 24$ hours) suppressed expressions of iNOS, NF- $\kappa \mathrm{B}$ p65, p-IкB, nucleotide-binding domain-like receptor protein 3 (NLRP3), caspase-1 and ASC. These results proved that polydatin alleviated inflammation through regulating NF$\mathrm{B}$ pathway and NLRP3 inflammasome pathway. ${ }^{97}$

Paeoniflorin is a monoterpene glucoside mainly existing in roots of Paeonia plants. It has been reported to possess good anti-inflammation and immune regulation activities. ${ }^{98}$ In SCI rats, paeoniflorin $(20,50 \mathrm{mg} / \mathrm{kg} / \mathrm{day}$, i.p.) treatment significantly decreased expressions of iNOS, COX-2 in spinal cord at day 7 and 14 post-injury. In in vitro experiments, mRNA expressions of $1 \mathrm{~L}-1 \beta$, IL-6 and TNF- $\alpha$ were suppressed after pre-treating with paeoniflorin $(200 \mu \mathrm{mol} / \mathrm{L}, 2$ hours $)$ in PC12 cells. Besides, decrease of nuclear Nrf2, as well as increases of NF- $\mathrm{KB}$ p65, NLRP3, caspase-1 and ASC expressions were reversed by paeoniflorin treatment. Thus, its mechanism 
was related with suppressing activation of NLRP3 inflammasome pathway and NF-kB pathway. ${ }^{99,100}$

Asiatic acid is extracted from Centella asiatica (Linn.) Urban. It is a pentacyclic triterpenoid compound with multiple pharmacological properties, including antiinflammatory actions. ${ }^{101}$ Asiatic acid $(30,75 \mathrm{mg} / \mathrm{kg} / \mathrm{day}$, intragastric administration (i.g.) 3 times; $75 \mathrm{mg} / \mathrm{kg}$, i.p. once) reduced levels of IL- $1 \beta$, IL-18, IL- 6 and TNF- $\alpha$ in spinal cord of SCI rats, which mechanism involved the activation of nuclear factor- (erythroid-derived 2-) like-2 factor (Nrf2). Its effects can also be attributed to the inhibition of NLRP3 inflammasome pathway, which activated caspase-1 and led to secretion of proinflammatory molecules, such as IL-1 $\beta$ and IL-18. ${ }^{102,103}$

Rosmarinic acid is a polyphenol of the Lamiaceae family, which is richly present in rosemary, sage, lemon balm and thyme. As a natural antioxidant, rosmarinic acid is regarded as possessing biological effects against oxidative stress and inflammation, while its neuroprotection effect has also been investigated in recent years. ${ }^{104}$ In SCI rats, rosmarinic acid $(10,20,40 \mathrm{mg} / \mathrm{kg}$, i.p. for 7 or 28 successive days) could inhibit microglia activation (labeled by Iba-1) and downregulate proinflammatory cytokine levels (IL-6, IL-1 $\beta$, TNF- $\alpha$ ). In LPS-induced PC12 cells, rosmarinic acid $(5,10,20 \mu \mathrm{g} / \mathrm{mL}, 24$ hours $)$ could inhibit TLR4/NF- $\kappa \mathrm{B}$ pathway, activate Nrf2/HO-1, and increase nuclear translocation of NF- $\mathrm{kB}$ p $65 .{ }^{105,106}$

Puerarin, a natural isoflavone, mainly exists in dried radix of Pueraria lobate (Wild.) Ohwi. It has been reported to effectively inhibit proinflammatory cytokine production and/or glia cell activation in a variety of diseases, including SCI. ${ }^{107}$ In spinal cord of SCI rats, the increase of positive area of GFAP and OX-42/Iba-1 were significantly reversed by puerarin $(50,100 \mathrm{mg} / \mathrm{kg}$, i.p. for 28 days; 4, 20, $100 \mathrm{nM}$, i.t. for 7 days). Puerarin also attenuated the levels and mRNA expression of inflammatory cytokines, including TNF- $\alpha$, IL- $1 \beta$ and IL-6. Its effect on glial activation and up-regulation of inflammatory cytokines were associated with activation of PI3K/Akt pathway and suppression of NF- $\kappa \mathrm{B}$ pathway. ${ }^{108,109}$

Plumbagin is isolated from root of Plumbago zeylanica L., possessing potent antitumor activity. ${ }^{110}$ It also exerts anti-inflammatory effect after SCI. Plumbagin $(20 \mathrm{mg} / \mathrm{kg}$, intraspinal injection or i.p. for 5 days) could downregulate the levels of proinflammatory cytokines (TNF- $\alpha$, IL-1 $\beta$ ), and expressions of NF- $\mathrm{kB}, \mathrm{Nrf2}$, p-Akt and p-ERK in spinal cord. ${ }^{111,112}$
As the major component of garlic, allicin is reported to have important health benefits and medicinal effects. In SCI mice and rats, allicin $(10,50 \mathrm{mg} / \mathrm{kg}$, i.p.) significantly increased heat shock protein 70 (HSP70) expression, and reduced iNOS expression in spinal cord tissue. ${ }^{113}$ Allicin $(10,50 \mathrm{mg} / \mathrm{kg}$, i.p. once daily for 21 days) also further increased Nrf2 nuclear translocation in neuron and astrocytes. siRNA-mediated Nrf2 gene knockdown completely blocked its effect. ${ }^{114}$ In primary cultured spinal cord neurons, allicin $(50 \mu \mathrm{mol} / \mathrm{L}, 30$ minutes $)$ increased both mRNA and protein expression of HSP70, while it decreased protein expression of iNOS. Knockdown of HSP70 by siRNA partially nullified the regulation of allicin on iNOS. ${ }^{115}$

Tocotrienol is an isomer of vitamin E, which mainly exists in palm oil and rice bran oil, possessing antioxidative, ${ }^{116}$ anti-tumor ${ }^{117}$ and neuroprotective ${ }^{118}$ activities. In SCI rats, tocotrienol $(120 \mathrm{mg} / \mathrm{kg} /$ day, i.v. once daily for 8 weeks) significantly reduced iNOS activity, plasma NO production, and serum TNF- $\alpha$, IL-1 $\beta$, IL-6

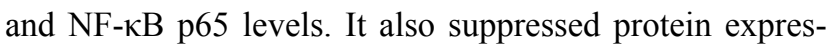
sions of TGF- $\beta$, collagen type IV and fibronectin in spinal cord tissues. ${ }^{119}$ These results verified its effects in treating neuroinflammation after SCI.

Resveratrol is a natural polyphenol presented in grapes, berries, peanuts and wine. It is characterized by antiproliferation, ${ }^{120}$ antioxidation ${ }^{121}$ and anti-inflammation. ${ }^{122}$ After SCI, resveratrol treatment $(200 \mathrm{mg} / \mathrm{kg}$; i.p., 3 times per day for 3 days) potentially hindered the formation of NLRP2 inflammasome in astrocytes, suppressed protein expressions of inflammatory factors (TNF- $\alpha$, IL-1 $\beta$, IL-10), and relieved neutrophil infiltration to inhibit inflammation cascade in rats' spinal cord. ${ }^{123,124}$ Resveratrol (100 mg/kg; i.p., 1, 24, 48 hours after SCI) also could enhance silent information regulator 1 (SIRT1) and adenosine monophosphate activated protein kinase (AMPK) expressions. AMPK activation increased $\mathrm{NAD}+/ \mathrm{NADH}$ ratio and triggered its downstream; whereas SIRT1 acted as an anti-inflammatory NAD+-dependent deacetylating enzyme via direct deacetylation of NF- $\mathrm{KB}$ p 65 . Thus, resveratrol inhibited NF- $\kappa \mathrm{B}$ activity via activating SIRT1-AMPK signaling pathway, then exerting its beneficial effects on alleviation of neuroinflammation. ${ }^{125,126}$

\section{Natural Compounds Targeting Both BSCB and Gliacytes After SCI}

Epigallocatechin gallate (EGCG) is a natural polyphenol, which mainly exists in green tea. In SCI rats, EGCG could 
(100 mg/kg, i.p. for 2 days) alleviate spinal cord edema, verified by reducing spinal cord water content and increasing AQP4 expressions at 24, 48 and 72 hours after injury. ${ }^{127}$ Meanwhile, EGCG could (100 mg/kg, i.p. for 2 days) activate astrocytes 24,48 and 72 hours post-SCI, proven by the increase of GFAP expression. It also downregulated IL-6, IL-2, MIP1 $\alpha$ and RANTES levels on day 1 and 3, while upregulated IL-4, IL-12 p70 and TNF- $\alpha$ in spinal tissues on day 1 after SCI. These effects on inflammatory cytokines may be related to its modulation on polarized states of macrophage, verified by changes of gene expressions of M1 and M2 phenotypes (CD86, Inf5, CD163, Mrc1). Meanwhile, EGCG could decrease nuclear translocation of subunit p65 (RelA) of the NF-kB dimer, thus inactivating NF- $\mathrm{kB}$ pathway. ${ }^{128}$

Curcumin is a representative polyphenolic component isolated from dried rhizome of Curcuma longa L. In previous studies, curcumin exerted positive effects on cerebral ischemia and traumatic brain injury, which were similar to SCI. ${ }^{129,130}$ After curcumin treatment post-SCI $(150,300 \mathrm{mg} / \mathrm{kg} /$ day, i.p. for 3 days), EB leakage into spinal cord tissue was significantly reduced at day 1 and day 7. Meanwhile, curcumin increased expressions of ZO1, occludin and HO-1, and this effect could be blocked by HO-1 inhibitor (zinc protoporphyrin). ${ }^{131,132}$ These results indicated that its therapeutic effect on SCI is associated with improvement on BSCB integrity. In aspect of antiinflammatory effect, curcumin $(40 \mathrm{mg} / \mathrm{kg}$, i.p.; 300,100 , $30 \mathrm{mg} / \mathrm{kg} /$ day, i.p. for 7 days) could reduce release of proinflammatory mediators in vivo, which was verified by the proteins and mRNA expression changes of TNF- $\alpha, 1 \mathrm{~L}-1 \beta$, NF- $\mathrm{KB}$ p65 and transforming growth factor (TGF)- $\beta_{1}$, TGF- $\beta_{2}{ }^{131,133}$ Similar results were observed in microglial cells in vitro. Knockdown of miR-199b-5p and overexpression of IKK $\beta$ both reversed suppression of curcumin $(8 \mu \mathrm{mol} / \mathrm{L})$ on inflammatory response and NF- $\mathrm{KB}$ activation. $^{134}$

Eugenol (4-allyl-2-methoxy-phenol) is a natural phenolic compound isolated from clove (Eugenia caryophyllata Thunb.), cinnamon (Cinnamomum cassia Presl), basil (Ocimum basilicum L.) and nutmeg (Myristica fragrans Houtt.). ${ }^{135}$ Evaluating by water content and EB leakage in rats' spinal tissues, BSCB permeability markedly decreased after administration of eugenol for 5 weeks $\left(50 \mathrm{mg} / \mathrm{kg} / \mathrm{day}\right.$, intravenous injection (i.v.)). ${ }^{136}$ Eugenol significantly suppressed the increase of pro-inflammation cytokines (TNF- $\alpha$, IL-1 $\beta$, IL-6) and NF- $\kappa B$ p65 expressions. It also reversed the increase of p-MAPK and caspase- 3 protein levels induced by SCI. These results revealed that eugenol may have exerted protective action on BSCB through NF- $\mathrm{KB}$ and MAPK signaling pathways. ${ }^{136}$

Gastrodin (4-hydroxybenzyl alcohol-4O- $\beta$-D-glucopyranoside) is a phenolic glycoside isolated from dried tuber of Gastrodia elata Bl. According to previous reports, gastrodin possesses various pharmacological properties, including sedative, hypnotic, analgesic, anti-vertigo, antiepileptic, anti-depressant, anti-aging and anti-hypertensive effects. ${ }^{137}$ In a study by Du, gastrodin $(100,200 \mathrm{mg} / \mathrm{kg} /$ day, i.p. for 5 days) could suppress the increase of EB content in spinal cord after injury. Meanwhile, gastrodin also decreased TNF- $\alpha$, IL-1 $\beta$ mRNA and increased Nrf2 mRNA expression, compared with SCI model group. Thus, gastrodin exerts therapeutic effects on SCI through activating Nrf2 signaling pathway and inhibiting inflammation-relation factors, leading to decreased BSCB permeability. ${ }^{138}$

D1-3-n-butylphthalide is a potent natural free radical scavenger, which was initially isolated from the seed of Apium graveolens Linn. In relation to BSCB restoration, Dl-3-n-butylphthalide ( $80 \mathrm{mg} / \mathrm{kg} /$ day, i.g.) could attenuate the increase of BSCB permeability, evaluated by decrease of EB content, increase of AJ proteins ( $\beta$-catenin, p120catenin) and TJ proteins (claudin-5, occludin) expressions in spinal cord tissues 24 hours post-SCI. ${ }^{139,140}$ Its effects were verified in vitro. Dl-3-n-butylphthalide ( $30 \mu \mathrm{mol} / \mathrm{L}, 6$ hours) degraded TJ (claudin-5, occludin) and AJ ( $\beta$-catenin, p120-catenin) proteins in human BMECs. ${ }^{140}$ Similar results also have been observed in rats with chronic hypoperfusion brain injury. ${ }^{141}$ In relation to activation of gliacytes, effects of Dl-3-n-butylphthalide also have been investigated. Oral administration of D1-3-n-butylphthalide ( $80 \mathrm{mg} / \mathrm{kg} /$ day) restrained activation of microglia (Iba-1 as marker), reduced the release of inflammatory cytokines (TNF- $\alpha$, IL-6, IL-1 $\beta$ ) in rats' spinal tissues 1 day postSCI. Its mechanism was associated with reversing the upregulation of TLR4/NF- $\kappa B$ signaling pathway in microglia. Effects of Dl-3-n-butylphthalide (30 uM) were verified in co-culture system of BV-2 cells and PC12 cells after LPS stimulation. ${ }^{142}$

Baicalin is a flavonoid compound derived from Scutellariae radix, the dried root of Scutellaria baicalensis Georgi. Baicalin possesses potent pharmacological properties, such as anti-tumor, antioxidant and anti-microbial. Baicalin can pass through $\mathrm{BBB} / \mathrm{BSCB}$, which provides an absolute advantage for treatment of neurodegenerative 
diseases and CNS trauma. ${ }^{143}$ After administration of baicalin $(10,30,100 \mathrm{mg} / \mathrm{kg} /$ day, i.p.), water content and EB leakage dose-dependently decreased, compared with SCI group. ${ }^{144}$ In both in vitro and vivo experiments, up-regulation of TJ proteins (claudin-5 and ZO-1) expressions and down-regulation of MMP-9 expression on BBB were also observed following baicalin treatment $(5,10,20 \mu \mathrm{g} / \mathrm{mL}$, 24 hours). ${ }^{145,146}$ These results confirmed the restorative effects of baicalin on BSCB. In the other part, substantial increase trend of proteins and mRNA expressions of IL$1 \beta$, IL-6, TNF- $\alpha, \mathrm{NF}-\kappa \mathrm{B}$ p50 and NF- $\mathrm{B}$ p 65 in spinal tissues were dramatically reversed after administration of baicalin (10, 30, $100 \mathrm{mg} / \mathrm{kg} /$ day, i.p.; 50, $100 \mathrm{mg} / \mathrm{kg} /$ day, i. g.). ${ }^{144,147}$

Astragaloside IV is a natural saponin isolated from dried root of Astragalus membranaceus (Fisch.) Bge. var. mongholicus (Bge.) Hsiao, or Astragalus membranaceus (Fisch.) Bge. ${ }^{148}$ In the fields of SCI treatment, astragaloside IV could induce M2 microglial polarization to M2 phenotype, by up-regulating markers of M2 (Arg-1, Ym-1) and down-regulating markers of M1 (CD16/32). Thus, expressions of pro-inflammatory mediators were inhibited, including iNOS, COX-2 and TNF- $\alpha$. The anti-inflammatory effect is associated with suppressing phosphorylation levels of mTORC1/p70S6K signaling, which was verified both in HAPI cells $(1,10 \mu \mathrm{mol} / \mathrm{L}, 24$ hours) and spinal tissues of SCI rats $(10 \mathrm{mg} / \mathrm{kg} /$ day, i.p. $){ }^{149}$ Besides, astragaloside IV (30 mg/kg, i.g.) attenuated the dysfunction of TJ proteins (claudin-5, ZO-1) ${ }^{150}$ and gap junction proteins (connexin-43) ${ }^{151}$ in spinal tissues by suppressing $\mathrm{K}_{\mathrm{ATP}} /$ JNK pathway, which was beneficial for BSCB restoration.

Oleanolic acid (3 $\beta$-hydroxyolean-12-en-28-oic acid) is a natural triterpenoid, which exists either as a free acid or as an aglycone precursor for triterpenoid saponins. It is widely found in various kinds of medical herbs and vegetables, such as fruits of olives (Olea europaea L.) and glossy privet (Ligustrum lucidum Ait.). Oleanolic acid has exhibited various kinds of pharmacological effects, such as inflammation suppression, tumor growth reduction and hepatoprotective effects. ${ }^{152}$ In experimental autoimmune encephalomyelitis (EAE), after administration of oleanolic acid (50 mg/kg/day, i.p. for 7 days), reduction of EB leakage and lower infiltration of inflammatory cells in CNS were observed. ${ }^{153}$ These results hint at effects of oleanolic acid on CNS-barrier integrity, which is directly related to BSCB breakdown after SCI. In studies of Wang et al., treatment of oleanolic acid $(25,50,100 \mathrm{mg} / \mathrm{kg}$, i.p. for 6 weeks) could dose-dependently down-regulate EB contents and inflammatory cytokine (TNF- $\alpha$, IL-6, IL-1 $\beta$ ) levels in spinal tissue, indicating decrease of BSCB permeability and alleviation of neuroinflammation. Its mechanism was related to inhibition of MAPKs and NF$\kappa \mathrm{B}$ signaling pathways in SCI mice, as evidenced by the down-regulated phosphorylation of p38, c-Jun-NH 2 term-

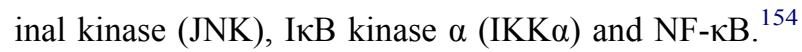

Lycopene is a natural carotenoid mostly found in tomato, watermelons and papayas, and proves useful in managing neurodegenerative disorders. ${ }^{155}$ BSCB restoration is an effective pathway for lycopene in SCI treatment. In study of Zhang et al., consecutive administration of lycopene (4 mg/kg/day, i.p.) significantly decreased BSCB permeability and water content of spinal cord in SCI mice, evaluated by EB leakage and wet/dry weight method respectively. Besides, lycopene could also upregulate TJ proteins (ZO-1, claudin-5) and downregulate HO-1 level in SCI rats. ${ }^{156}$ Regarding anti-inflammatory properties, lycopene treatment $(25,50 \mathrm{mg} / \mathrm{kg}$; i.g. for 14 days) significantly suppressed the protein levels increase of COX-2, TNF- $\alpha$, IL-1 $\beta$, IL-6, IL- 8, NF- $\kappa$ B and activated protein-1 in spinal tissues 14 days after injury. ${ }^{156,157}$

Rutin, also called rutoside, is a flavonoid existing in many foods and plants, such as buckwheat, tea and apple. It shows satisfactory anti-inflammatory, antioxidant, antitumor, antiviral and immunomodulatory effects. ${ }^{158}$ Administration of rutin $(1,10 \mu \mathrm{mol} / \mathrm{kg}$, i.p.) could attenuate water content and MMP-9 expression in rats' spinal tissues 6 hours post-SCI. ${ }^{159}$ These results verified its effects on $\mathrm{BSCB}$ restoration. In addition, rutin $(50,100$ $\mathrm{mg} / \mathrm{kg}$, i.p. for 3 days) significantly reduced levels of inflammatory cytokines (IL-1 $\beta$, IL-18, TNF- $\alpha$ ) and chemokines (macrophage inflammatory proteins-2 (MIP-2/ CXCL2)) in spinal tissues. Maturation and secretion of IL-1 $\beta$ and IL-18 are mediated by NLRP3 inflammasome. As a signaling complex, NLRP3 inflammasome is assembled after stimulus, which consists of caspase-1, NLRP3 and apoptosis-associated speck-like protein (ASC). Rutin also attenuated expressions of caspase-1, NLRP3 and ASC, which revealed its mechanism of antiinflammatory effect after SCI. ${ }^{160}$

Quercetin is a kind of flavonoid found in a variety of vegetables, beverages, fruits and herbs, which is safe for human application. It has been confirmed to exhibit an anti-inflammatory effect in many diseases, including SCI. After SCI, quercetin $(25 \mu \mathrm{mol} / \mathrm{kg}$, i.p. twice daily; $200 \mathrm{mg} /$ $\mathrm{kg}$, i.p.) attenuated the recruitment of neutrophils, polymorphonuclear leukocytes, and macrophages/microglia to 
the white matter of the lesion site. ${ }^{161,162}$ At the lesion site, astrocytes were activated after injury, labeled by GFAP and S100. Quercetin $(20 \mathrm{mg} / \mathrm{kg}$, i.p. for 7 days) could further increase the change trend. ${ }^{163}$ Quercetin $(7.5 \mathrm{mg} /$ $\mathrm{kg}$, i.p. twice daily for 10 days) also promoted microglia polarizing from M1 (labeled with Arg-1) to M2 (labeled with iNOS) phenotype through inhibition of STAT1 and NF- $\mathrm{KB}$ pathway in vivo and in vitro. ${ }^{164}$ Besides, quercetin $(100 \mathrm{mg} / \mathrm{kg}$, i.p. twice daily for 3 days) inhibited NLRP3 inflammasome activation and reduced the proinflammation cytokines levels (IL-1 $\beta$, IL-18, TNF- $\alpha$ ) in spinal cord tissue at 72 hours after SCI. ${ }^{165}$

To summarize, the sources, structure, doses, and mechanisms of 16 natural compounds on neuroinflammation after SCI are summarized in Table 1.

\section{Modulatory Effects of Plants and Chinese Herb Extracts on Neuroinflammation After SCl}

Green tea polyphenols (GTP) is a category of natural polyhydroxy phenolic compounds derived from fresh leaves of green tea. EGCG is the main constituent and also effective in SCI treatment, by targeting BSCB and gliacytes activation. According to previous studies, GTP acted as a potential neuroprotective agent against BBB disruption at early stage of focal cerebral ischemia by regulating TJs (claudin-5, occludin, ZO-1) and caveolin-1 expressions. Its mechanism is associated with attenuating PKC $\alpha$ expression and phosphorylated ERK1/2. ${ }^{166,167}$ Considering the similarity between BBB and BSCB, same effects are observed on improving BSCB integrity. In Yu's study, BSCB permeability in SCI rats was decreased after administration of GTP $(400 \mathrm{mg} / \mathrm{kg} / \mathrm{day}$, i. g., twice a day for 30 days), measured by EB leakage and water content. Decreased trend of TJ proteins level (ZO-1, occludin, claudin-5) was also reversed after GTP intervention, and inhibition of NF- $\mathrm{BB}$ signaling pathway was involved in the modulation process. ${ }^{168}$

WIB-801C, a standardized and n-butanol extract of caterpillar fungus (C. militaris) contains about $7-8 \%(\mathrm{w} /$ w) cordycepin. After administrating SCI rats with WIB $801 \mathrm{C}(50 \mathrm{mg} / \mathrm{kg}$, i.g. for 2 weeks), increase of BSCB permeability was significantly reversed, evaluated by EB dye extravasation and MMP-9 expression in spinal cord. In addition, it ameliorated neuroinflammatory response after SCI by suppressing inflammatory cytokines (TNF- $\alpha$, IL-1 $\beta$, IL-6, COX-2) and chemokines (Gro- $\alpha / C X C L 1$,
Mip-2 $\alpha$ ). Infiltration of neutrophils and macrophage was also notably suppressed by WIB-801C at day 1 and day 5 after SCI, respectively. All these results were associated with inhibition of $\mathrm{p} 38 \mathrm{MAPK}$ activation and proNGF production in microglia, which eventually led to improvement of functional recovery after SCI. ${ }^{169}$

Angelica dahuricae radix (ADR) is the dried root of Angelica sinensis (Oliv.) Diels, which exhibits liver protective, anti-microbial, anti-mutagenic and anti-inflammatory effects. ${ }^{170}$ In the field of SCI treatment, ADR extract inhibited mRNA and protein expressions of proinflammatory mediators (TNF- $\alpha$, IL- $1 \beta$, IL-6, iNOS, COX-2) both in LPS-activated BV-2 cells $(10,50 \mu \mathrm{g} / \mathrm{mL}$ for 30 minutes $)$ and spinal cord of SCI rats $(100 \mathrm{mg} / \mathrm{kg} /$ day, i.g., once per day for 2 weeks). Its mechanism was investigated in SCI rats, by suppressing p38MAPK activation and pro-NGF expression. ${ }^{171}$

Lycium barbarum, also named Fructus Lycii or Wolf berry, is the fruit of Lycium barbarum L. It is believed to be beneficial to eye, kidney and liver. ${ }^{172}$ As the main constituent, Lycium barbarum polysac charide (LBP) exerted satisfactory activities of immune regulation and gliacytes activation. In the chronic stage of SCI, LBP significantly activated microglia (labeled with ED-1, lysosomal membrane marker) and downregulated M1/M2 ratio (iNOS/Arg1). These results were both verified in SCI rats $(10 \mathrm{mg} / \mathrm{kg}$, i.g., twice a day) and N9 microglial cells (100 $\mu \mathrm{g} / \mathrm{mL}$ ). However, no significant effect was observed on astrocytes. ${ }^{173}$

Silymarin is a mixture of 7 flavonolignans and polyphenols, purified from Silybum marianum (Linn.) Gaertn. Its main component of silymarin complex is silybin, forming up to $80 \%$ of standardized extracts. Silymarin has been proved to have antioxidative activity, and has been used to treat liver diseases for a long time. ${ }^{174}$ Its effectiveness in protection of spinal cord is also investigated. Silymarin (30, $120 \mu \mathrm{mol} / \mathrm{L}$; i.t., 5 minutes after SCI) reversed the increase of ED-1 positive microglia in rats' spinal cord tissues 3 days after SCI. In primary rat glial cell and microglia, silymarin $(20,40,80 \mu \mathrm{mol} / \mathrm{L})$ inhibited their proliferation in a concentration-dependent manner. It also reduced protein expressions of iNOS and IL- $1 \beta$, mediated through NF- $\mathrm{KB}$ and PKC pathways. ${ }^{175}$

Effect of baicalin on neuroinflammation after SCI has been mentioned above. Beside the active constituent, total extract of Scutellariae Radix also exhibits satisfactory effects. In spinal tissues of SCI rats, administration of ethanol extract of Scutellariae Radix (EESB; $100 \mathrm{mg} / \mathrm{kg} /$ 


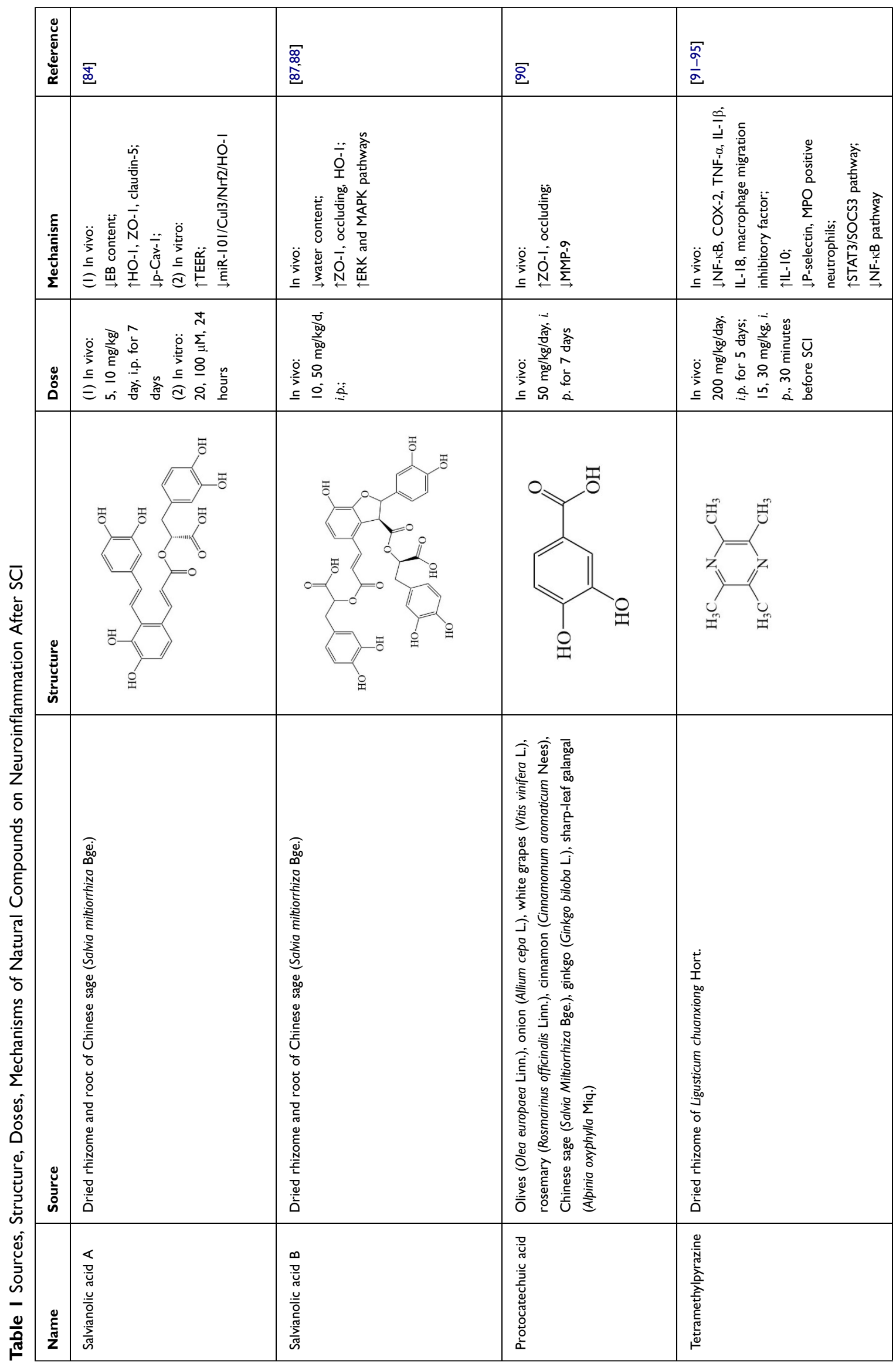


$\underline{\text { Dovepress }}$

Wu et al

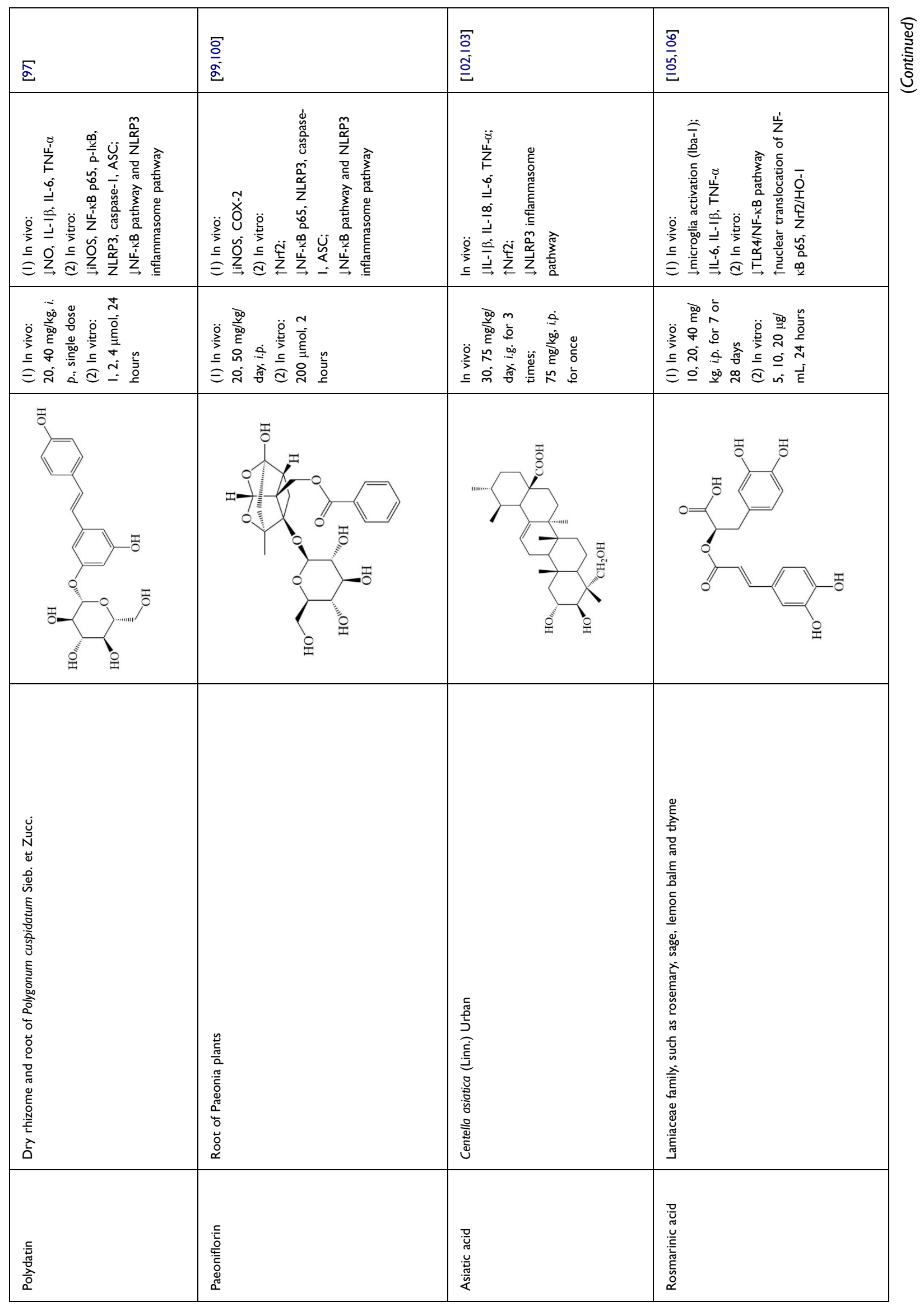

Journal of Inflammation Research 2021:14

https://doi.org// 0.21 47//IR.S329864

$\mathbf{5 7 2 5}$ 


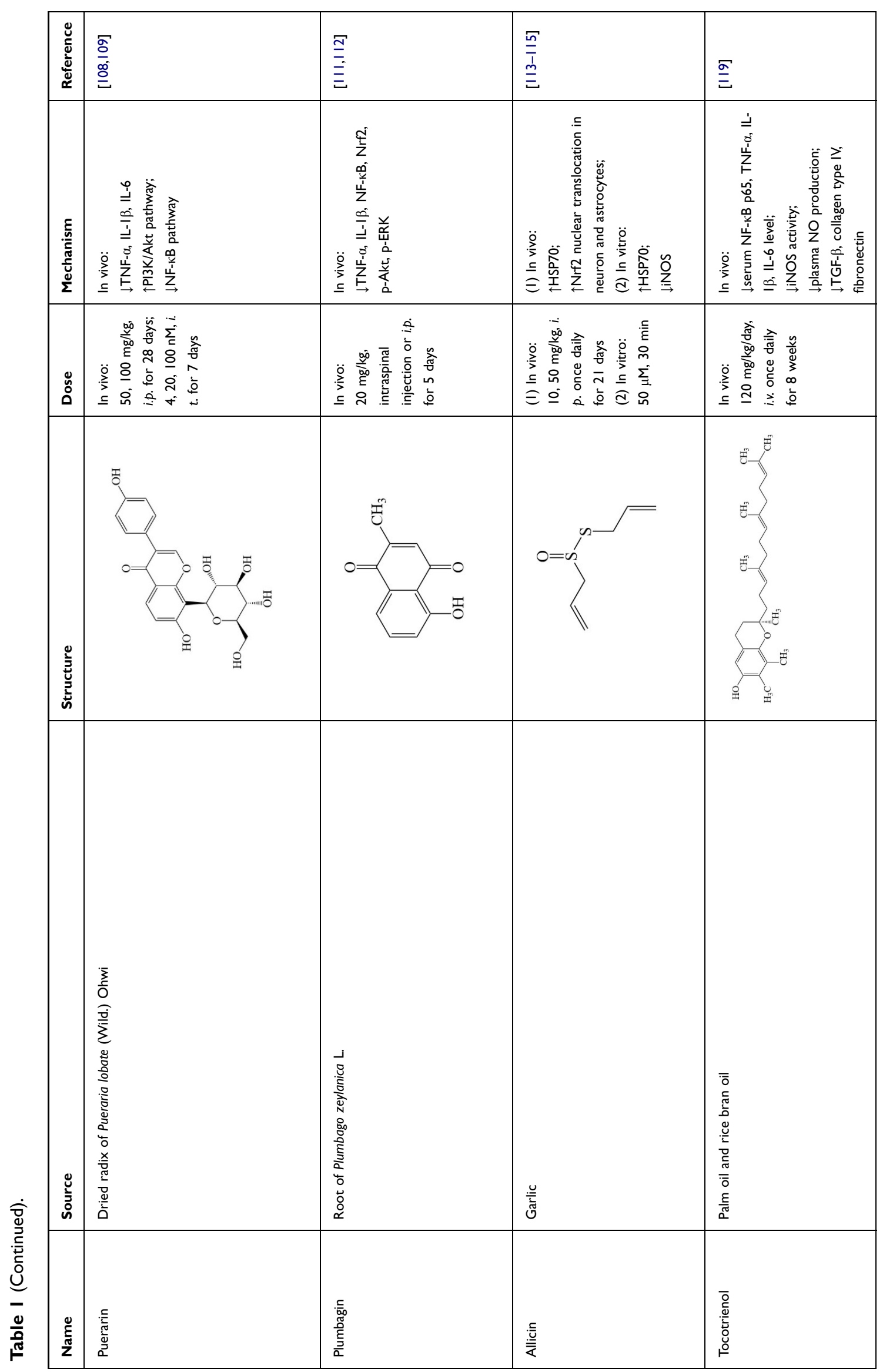




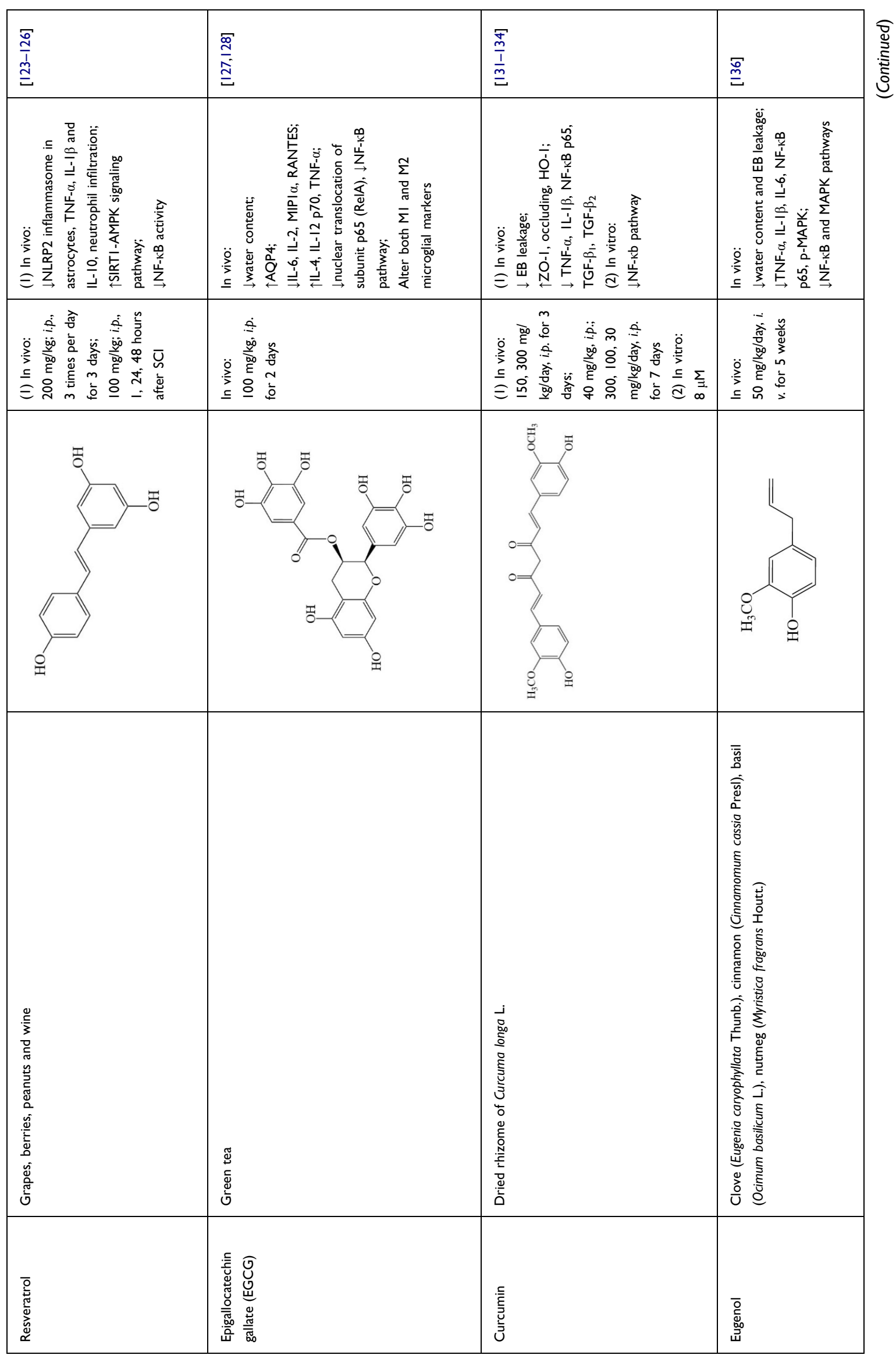




\begin{tabular}{|c|c|c|c|c|}
\hline 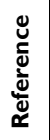 & 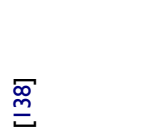 & $\begin{array}{l}\frac{1}{1} \\
\frac{1}{2} \\
\underline{m}\end{array}$ & 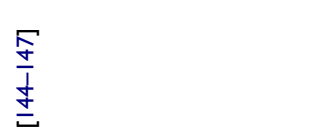 & 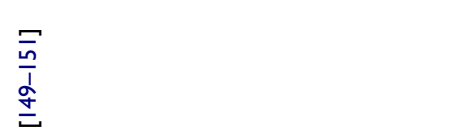 \\
\hline 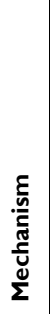 & 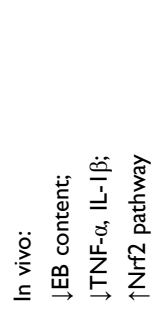 & 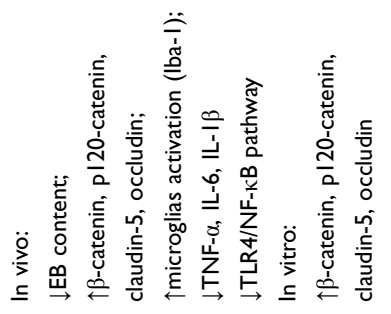 & 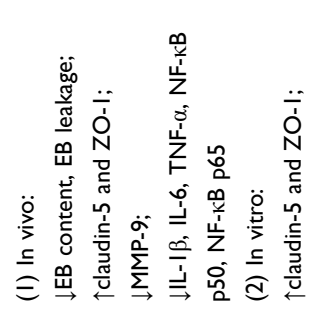 & 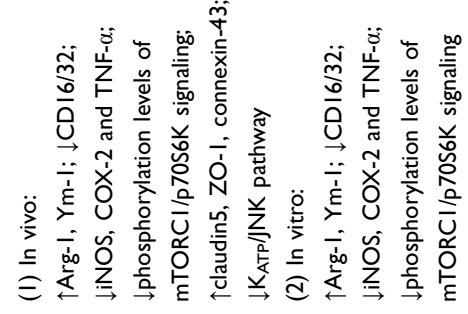 \\
\hline ڤั̀ & 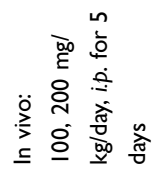 & 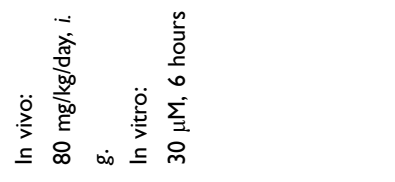 & 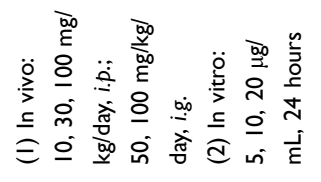 & 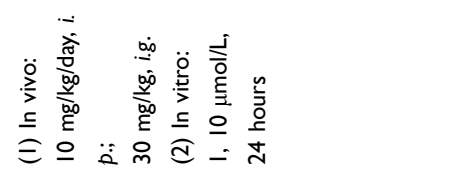 \\
\hline 总 & 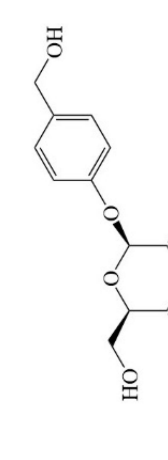 & & 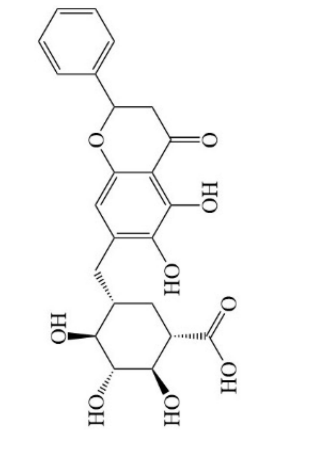 & \% \\
\hline ڤัٌ & 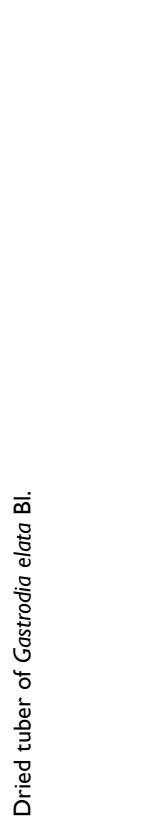 & 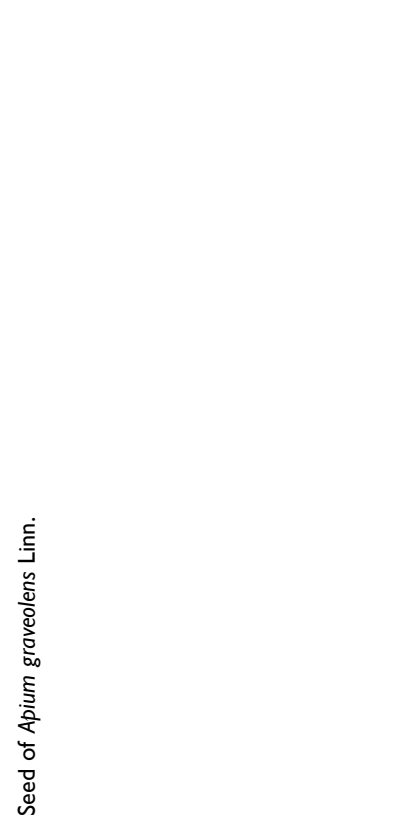 & 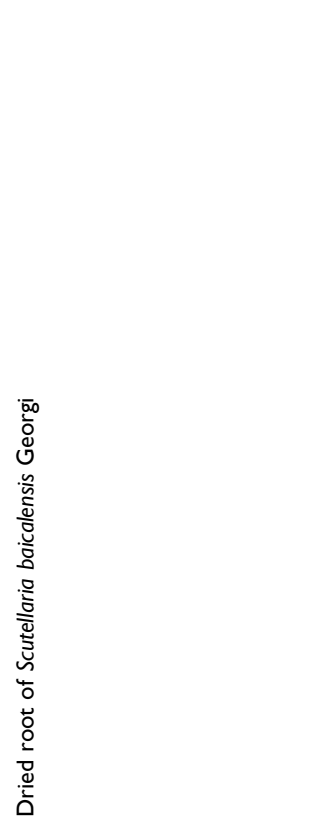 & 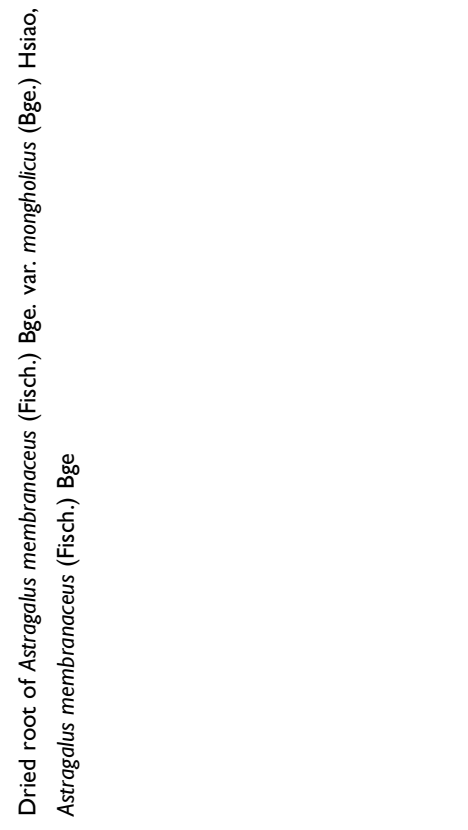 \\
\hline 童 & $\begin{array}{l}\text { 들 } \\
\text { o } \\
\text { 产 } \\
\text { ज̃ }\end{array}$ & 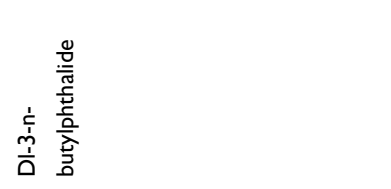 & 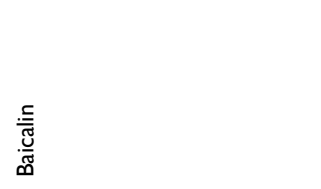 & 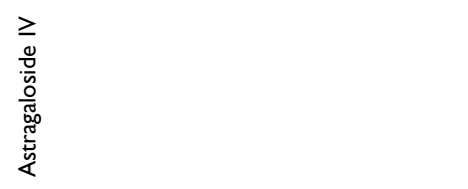 \\
\hline
\end{tabular}




\begin{tabular}{|c|c|c|c|}
\hline 急 & 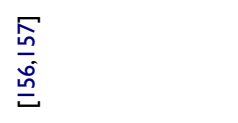 & 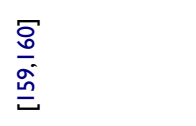 & $\begin{array}{l}\frac{\sqrt{0}}{\frac{1}{1}} \\
\frac{1}{6}\end{array}$ \\
\hline 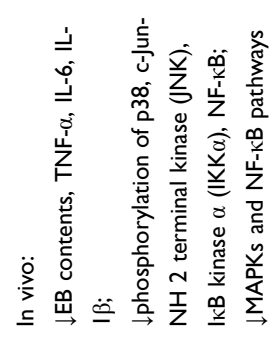 & 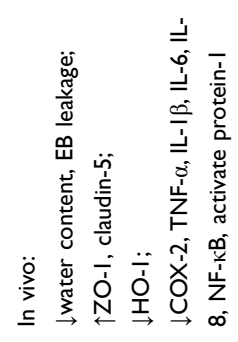 & 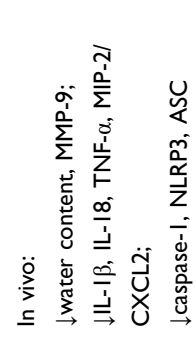 & 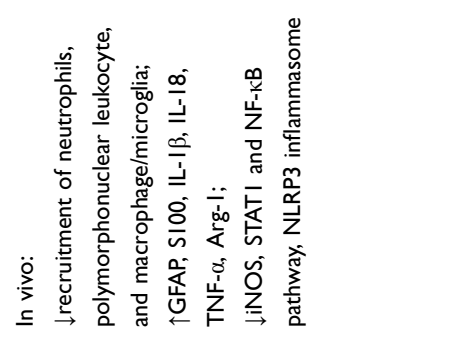 \\
\hline 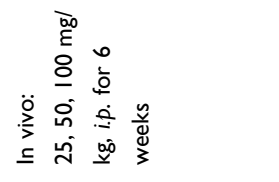 & 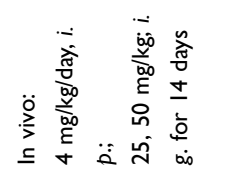 & 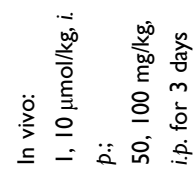 & 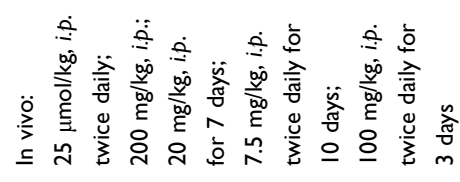 \\
\hline , & & & $=$ \\
\hline 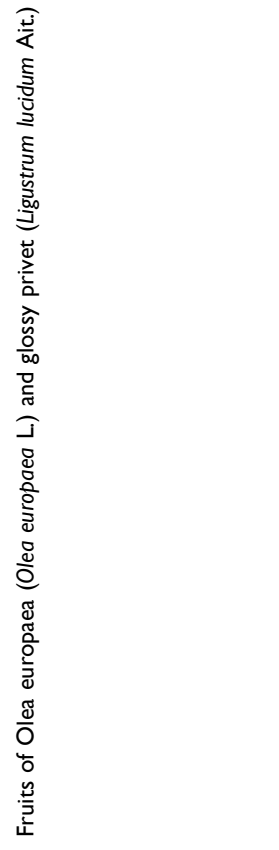 & 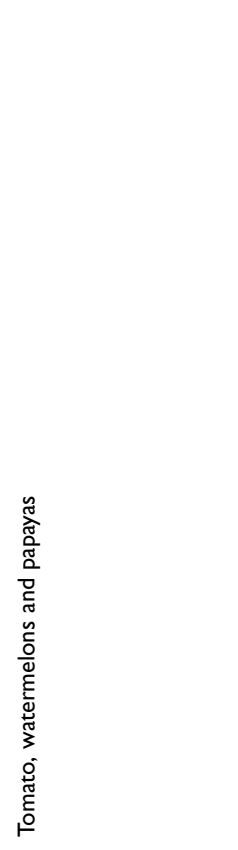 & 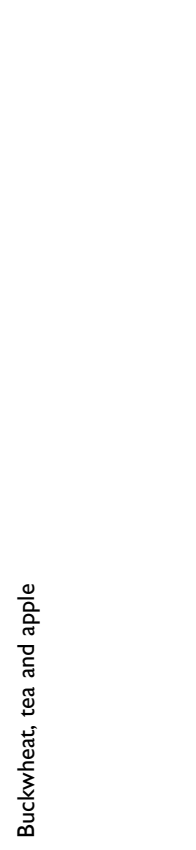 & $\begin{array}{l} \\
\\
\\
\end{array}$ \\
\hline 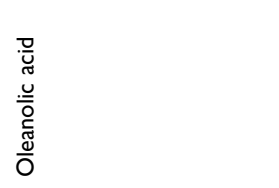 & 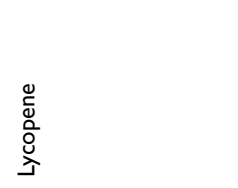 & 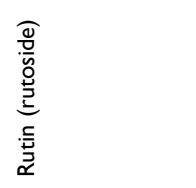 & 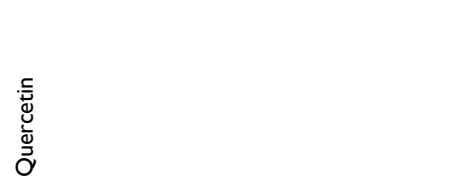 \\
\hline
\end{tabular}


Table 2 Sources, Doses, Mechanisms of Plants and Chinese Herb Extracts on Neuroinflammation After SCl

\begin{tabular}{|c|c|c|c|c|}
\hline Name & Source & Dose & Mechanism & Reference \\
\hline Green tea polyphenols & Fresh leaves of green tea & $\begin{array}{l}\text { In vivo: } \\
400 \mathrm{mg} / \mathrm{kg} / \text { day, i.g., } \\
\text { twice a day for } 30 \text { days }\end{array}$ & $\begin{array}{l}\text { In vivo: } \\
\downarrow \text { EB leakage, water } \\
\text { content; } \\
\uparrow Z O-I \text {, occludin, claudin- } \\
5 ; \\
\downarrow N F-\kappa B \text { pathway }\end{array}$ & [168] \\
\hline WIB-80IC & $\begin{array}{l}\mathrm{n} \text {-butanol extract of caterpillar fungus ( } C \text {. } \\
\text { militaris) }\end{array}$ & $\begin{array}{l}\text { In vivo: } \\
50 \mathrm{mg} / \mathrm{kg} \text {, o.p. for } 2 \\
\text { weeks }\end{array}$ & $\begin{array}{l}\text { In vivo: } \\
\downarrow \text { EB dye extravasation, } \\
\text { MMP-9; } \\
\downarrow \text { TNF- } \alpha, \text { IL-I } \beta, \text { IL-6, COX- } \\
2 \text {, Gro- } \alpha / C X C L I, \text { Mip- } 2 \alpha \text {; } \\
\downarrow \text { Infiltration of neutrophils } \\
\text { and macrophage }\end{array}$ & [169] \\
\hline Angelica dahuricae radix & Dried root of Angelica sinensis (Oliv.) Diels & $\begin{array}{l}\text { (I) In vivo: } \\
100 \mathrm{mg} / \mathrm{kg} / \text { day, i.g., } \\
\text { once per day for } 2 \\
\text { weeks } \\
\text { (2) In vitro: } \\
10,50 \mu \mathrm{g} / \mathrm{mL} \text { for } 30 \\
\text { minutes }\end{array}$ & $\begin{array}{l}\text { (I) In vivo: } \\
\downarrow T N F-\alpha, \text { IL-I } \beta, \text { IL-6, iNOS, } \\
\text { COX-2; } \\
\downarrow \text { P38MAPK activation, } \\
\text { pro-NGF } \\
\text { (2) In vitro: } \\
\downarrow T N F-\alpha, \text { IL-I } \beta, \text { IL-6, iNOS, } \\
\text { COX-2 }\end{array}$ & [171] \\
\hline $\begin{array}{l}\text { Lycium barbarum } \\
\text { (Fructus Lycii or Wolf } \\
\text { berry) }\end{array}$ & Fruit of Lycium barbarum $\mathrm{L}$. & $\begin{array}{l}\text { (I) In vivo: } \\
10 \mathrm{mg} / \mathrm{kg} \text {, i.g., twice a } \\
\text { day } \\
\text { (2) In vitro: } \\
100 \mu g / \mathrm{mL}\end{array}$ & $\begin{array}{l}\text { (I) In vivo: } \\
\uparrow E D-I ; \\
\downarrow \text { ratio of iNOS/Arg I } \\
\text { (2) In vitro: } \\
\uparrow E D-I ; \\
\downarrow \text { ratio of iNOS/ArgI }\end{array}$ & [173] \\
\hline Silymarin & $\begin{array}{l}\text { A mixture of } 7 \text { flavonolignans and polyphenols; } \\
\text { purified from Silybum marianum (Linn.) Gaertn }\end{array}$ & $\begin{array}{l}\text { (I) In vivo: } \\
30, I 20 \mu \mathrm{M} \text {; i.t., } 5 \\
\text { minutes after SCl } \\
\text { (2) In vitro: } \\
20,40,80 \mu \mathrm{M}\end{array}$ & $\begin{array}{l}\text { (I) In vivo: } \\
\downarrow \text { ED-I positive microglia } \\
\text { (2) In vitro: } \\
\downarrow \text { iNOS, IL-I } \beta, \text { NF- } \kappa B \text { and } \\
\text { PKC pathways }\end{array}$ & [175] \\
\hline Scutellariae radix & Ethanol extract of Scutellariae radix & $\begin{array}{l}\text { (I) In vivo: } \\
100 \mathrm{mg} / \mathrm{kg} / \text { day, once a } \\
\text { day for } 2 \text { weeks } \\
\text { (2) In vitro: } \\
5,10 \mu \mathrm{mol} / \mathrm{mL} \text { for } 30 \\
\text { minutes }\end{array}$ & $\begin{array}{l}\text { (I) In vivo: } \\
\downarrow T N F-\alpha, \text { IL-I } \beta, \text { IL-6, COX- } \\
\text { 2, iNOS } \\
\text { (2) In vitro: } \\
\downarrow T N F-\alpha, \text { IL-I } \beta, \text { COX-2, } \\
\text { iNOS }\end{array}$ & [119] \\
\hline S/B remedy & $\begin{array}{l}\text { Scutellariae radix Georgi and Bupleurum } \\
\text { scorzonerifolium Willd. in ratio of } 7: 3\end{array}$ & $\begin{array}{l}\text { (I) } \ln \text { vivo: } \\
20 \mathrm{mg} / \mathrm{kg} \text {, i.p. for } 7 \\
\text { days } \\
\text { (2) In vitro: } \\
10,20,40,80,100 \mu g / \\
\mathrm{mL}, 2 \text { hours }\end{array}$ & $\begin{array}{l}\text { (I) In vivo: } \\
\downarrow E D-I \\
\text { (2) In vitro: } \\
\uparrow \text { migratory of microglias, } \\
\text { ¿NOS and COX’-2 }\end{array}$ & [120] \\
\hline
\end{tabular}


day, i.g., once a day for 2 weeks) significantly decreased the mRNA and protein expressions of pro-inflammatory cytokines, including TNF- $\alpha$, IL-1 $\beta$, IL-6, COX-2 and iNOS. In LPS-stimulated primary microglia in vitro, pretreatment of $\operatorname{EEBS}(5,10 \mu \mathrm{mol} / \mathrm{mL}$ for 30 minutes $)$ also reversed the increase of $\mathrm{mRNA}$ and protein expressions of TNF- $\alpha$, IL-1 $\beta$, COX-2 and iNOS. ${ }^{176}$

A simplified remedy (abbreviated as $\mathrm{S} / \mathrm{B}$ ) has also been investigated in the field of SCI treatment, which consisted of Scutellariae radix Georgi and Bupleurum scorzonerifolium Willd. in ratio of 7:3. This remedy $(10,20,40,80$, $100 \mu \mathrm{g} / \mathrm{mL}, 2$ hours) could promote migration of microglia, as well as protein expressions of iNOS and COX-2 in LPS-stimulated primary neuron/microglia co-culture system. Administration of S/B remedy $(20 \mathrm{mg} / \mathrm{kg}$, i.p. for 7 days) to SCI rats also reduced the ED-1 level in spinal cord. ${ }^{177}$ This work further verified the anti-neuroinflammatory activity of Scutellariae radix.

To summarize, the pictures, sources, doses, and mechanisms of 7 plants and Chinese herb extracts on neuroinflammation after SCI are shown in Table 2. Compared with single natural compounds, plants and Chinese herb extracts have the superiority of synergistic effect and multitarget action. However, complicated interactions exist between the numerous compounds of plants and Chinese herbs. These may induce unpredictable side effects and are not negligible.

\section{Conclusion}

In this review, we provide an overview of the pathological process of neuroinflammation after SCI. On this basis, effects and mechanism of 25 natural compounds and 7 Chinese herb/plant extracts on neuroinflammation after SCI are summarized in detail. Although they exert antineuroinflammation effect by acting on multiple targets, most of them still are at preclinical stage. Only a few small-molecule drugs, such as zoledronic acid, minocycline, and vitamin D supplementation, have entered clinical trials. Broadly speaking, other treatment means account for the vast majority, such as umbilical cord mesenchymal stem cells, TNF- $\alpha$ monoclonal antibody, and rehabilitation therapy apparatus (https://clinicaltrials. gov). As a devastating traumatic disease of the CNS, it is difficult to complete healing SCI only by drug intervention. People have reached the consensus that combinations of multiple therapeutic methods will gain better results. Therefore, more compelling evidence and deep mechanisms studies are needed both in vivo and in vitro, in order to develop these natural products to potential drugs for SCI neuroinflammation treatment.

\section{Abbreviation}

ADR, Angelica dahuricae radix; AJ, adherens junction; AMPK, adenosine monophosphate activated protein kinase; Ang, angiopoietin; AQP-4, aquaporin-4; ASC, apoptosisassociated speck-like protein; BBB, blood-brain barrier; BMECs, brain microvascular endothelial cells; BSCB, blood-spinal cord barrier; Cav-1, caveolae-1; CLRs, C type lectin receptors; CNS, central nervous system; COX, cyclooxygenase; DAMPs, damage-associated molecular patterns; EB, Evans blue; EESB, ethanol extract of Scutellariae radix; EGCG, epigallocatechin gallate; ERK, extracellular signal-regulated kinase; GAP43, astrocytic growth-associated protein 43; GFAP, glial fibrillary acidic protein; GTP, green tea polyphenols; HMGB1, high-mobility group box 1 protein; HO-1, heme oxygenase-1; HSP70, heat shock protein 70; ICAM, intercellular cell adhesion molecule; IFN, interferon; i.g., intragastric administration; IKK $\alpha$, I $\kappa \mathrm{B}$ kinase $\alpha$; IL, interleukin; iNOS, inducible nitric oxide synthase; i.p., intraperitoneal injection; i.t., intrathecal injection; JNK, c-Jun-NH 2 terminal kinase; LBP, Lycium barbarum polysaccharide; LPS, lipopolysaccharide; MAPK, mitogen-activated protein kinase; MIP, macrophage inflammatory proteins-2; MMPs, matrix metalloproteinases; MPO, myeloperoxidase; NF- $\mathrm{B}$, nuclear factor kappa B; NLRP3, nucleotide-binding domain-like receptor protein 3; NLRs, Nod-like receptors; PMNs, polymorphonuclear leukocytes; PRRs, pattern recognition receptors; RLRs, RIG-like receptors; SCI, spinal cord injury; SIRT1, silent information regulator 1; TGF, transforming growth factor; TJ, tight junction; TLRs, Toll-like receptors; TNF- $\alpha$, tumor necrosis factor- $\alpha$; VCAM, vascular cell adhesion molecule; $\mathrm{ZnPP}$, zinc protoporphyrin.

\section{Acknowledgments}

This work was supported by National Natural Science Foundation of China (grant No. 81403278) and the Fundamental Research Funds for the Central Universities (grant No. GK202103079, GK202103074).

\section{Disclosure}

All authors declare that they have no competing interests.

\section{References}

1. Quadri SA, Farooqui M, Ikram A, et al. Recent update on basic mechanisms of spinal cord injury. Neurosurg Rev. 2020;43:425-441. doi:10.1007/s10143-018-1008-3 
2. Sun X, Jones ZB, Chen XM, et al. Multiple organ dysfunction and systemic inflammation after spinal cord injury: a complex relationship. J Neuroinflammation. 2016;13:260. doi:10.1186/ s12974-016-0736-y

3. Yong HYF, Rawji KS, Ghorbani S, et al. The benefits of neuroinflammation for the repair of the injured central nervous system. Cell Mol Immunol. 2019;16:540-546. doi:10.1038/s41423-0190223-3

4. Donnelly DJ, Popovich PG. Inflammation and its role in neuroprotection, axonal regeneration and functional recovery after spinal cord injury. Exp Neurol. 2008;209:378-388. doi:10.1016/ j.expneurol.2007.06.009

5. Jin X, Liu MY, Zhang DF, et al. Natural products as a potential modulator of microglial polarization in neurodegenerative diseases. Pharmacol Res. 2019;145:104253. doi:10.1016/j. phrs.2019.104253

6. Feng ST, Wang ZZ, Yuan YH, et al. Mangiferin: a multipotent natural product preventing neurodegeneration in Alzheimer's and Parkinson's disease models. Pharmacol Res. 2019;146:104336. doi:10.1016/j.phrs.2019.104336

7. Uchida Y, Yagi Y, Takao M, et al. Comparison of absolute protein abundances of transporters and receptors among blood-brain barriers at different cerebral regions and the blood-spinal cord barrier in humans and rats. Mol Pharm. 2020;17:2006-2020. doi:10.1021/acs.molpharmaceut.0c00178

8. Jin LY, Li J, Wang KF, et al. Blood-spinal cord barrier in spinal cord injury: a review. J Neurotrauma. 2021;38:1203-1224. doi:10.1089/neu.2020.7413

9. Maikos JT, Shreiber DI. Immediate damage to the blood-spinal cord barrier due to mechanical trauma. $J$ Neurotrauma. 2007;24:492-507. doi:10.1089/neu.2006.0149

10. Figley SA, Khosravi R, Legasto JM, et al. Characterization of vascular disruption and blood-spinal cord barrier permeability following traumatic spinal cord injury. $J$ Neurotrauma. 2014;31:541-552. doi:10.1089/neu.2013.3034

11. Yang Y, Estrada EY, Thompson JF, et al. Matrix metalloproteinase-mediated disruption of tight junction proteins in cerebral vessels is reversed by synthetic matrix metalloproteinase inhibitor in focal ischemia in rat. $J$ Cereb Blood Flow Metab. 2007;27:697-709. doi:10.1038/sj.jcbfm.9600375

12. Hsu J-YC, McKeon R, Goussev S, et al. Matrix metalloproteinase-2 facilitates wound healing events that promote functional recovery after spinal cord injury. $J$ Neurosci. 2006;26:9841-9850. doi:10.1523/JNEUROSCI.1993-06.2006

13. Lee JY, Choi HY, Ahn H-J, et al. Matrix metalloproteinase-3 promotes early blood-spinal cord barrier disruption and hemorrhage and impairs long-term neurological recovery after spinal cord injury. Am J Pathol. 2014;184:2985-3000. doi:10.1016/j. ajpath.2014.07.016

14. Yu F, Kamada H, Niizuma K, et al. Induction of MMP-9 expression and endothelial injury by oxidative stress after spinal cord injury. $J$ Neurotrauma. 2008;25:184-195. doi:10.1089/ neu.2007.0438

15. Wells JEA, Rice TK, Nuttall RK, et al. An adverse role for matrix metalloproteinase 12 after spinal cord injury in mice. $J$ Neurosci. 2003;23:10107-10115. doi:10.1523/JNEUROSCI.23-3110107.2003

16. Panahian N, Maines MD. Site of injury-directed induction of heme oxygenase- 1 and -2 in experimental spinal cord injury: differential functions in neuronal defense mechanisms? $J$ Neurochem. 2001;76:539-554. doi:10.1046/j.1471-4159.2001.00023.x

17. Lin Y, Vreman HJ, Wong RJ, et al. Heme oxygenase-1 stabilizes the blood-spinal cord barrier and limits oxidative stress and white matter damage in the acutely injured murine spinal cord. $J$ Cereb Blood Flow Metab. 2007;27:1010-1021. doi:10.1038/sj. jcbfm.9600412
18. Liu Y, Tachibana T, Dai Y, et al. Heme oxygenase-1 expression after spinal cord injury: the induction in activated neutrophils. $J$ Neurotrauma. 2002;19:479-490. doi:10.1089/ 08977150252932424

19. Lee T-S, Chau L-Y. Heme oxygenase-1 mediates the anti-inflammatory effect of interleukin-10 in mice. Nat Med. 2002;8:240 246. doi: $10.1038 / \mathrm{nm} 0302-240$

20. Herrera JJ, Sundberg LM, Zentilin L, et al. Sustained expression of vascular endothelial growth factor and angiopoietin-1 improves blood-spinal cord barrier integrity and functional recovery after spinal cord injury. $J$ Neurotrauma. 2010;27:2067-2076. doi:10.1089/neu.2010.1403

21. Nourhaghighi N, Teichert-Kuliszewska K, Davis J, et al. Altered expression of angiopoietins during blood-brain barrier breakdown and angiogenesis. Lab Invest. 2003;83:1211-1222. doi:10.1097/ 01.lab.0000082383.40635.fe

22. Han S, Arnold SA, Sithu SD, et al. Rescuing vasculature with intravenous angiopoietin- 1 and alpha $\mathrm{v}$ beta 3 integrin peptide is protective after spinal cord injury. Brain. 2010;133:1026-1042. doi:10.1093/brain/awq034

23. Cabrera-Aldana EE, Ruelas F, Aranda C, et al. Methylprednisolone administration following spinal cord injury reduces aquaporin 4 expression and exacerbates edema. Mediators Inflamm. 2017;2017:4792932. doi:10.1155/2017/4792932

24. Kimura A, Hsu M, Seldin M, et al. Protective role of aquaporin-4 water channels after contusion spinal cord injury. Ann Neurol. 2010;67:794-801. doi:10.1002/ana.22023

25. Pan Y-L, Guo Y, Ma Y, et al. Aquaporin-4 expression dynamically varies after acute spinal cord injury-induced disruption of blood spinal cord barrier in rats. Neuropathology. 2019;39:181186. doi:10.1111/neup. 12539

26. Kitchen P, Salman MM, Halsey AM, et al. Targeting aquaporin-4 subcellular localization to treat central nervous system edema. Cell. 2020;181:784-799. doi:10.1016/j.cell.2020.03.037

27. Zeng C-W, Kamei Y, Shigenobu S, et al. Injury-induced Cavlexpressing cells at lesion rostral side play major roles in spinal cord regeneration. Open Biol. 2021;11:200304. doi:10.1098/ rsob.200304

28. Shin T. Increases in the phosphorylated form of caveolin-1 in the spinal cord of rats with clip compression injury. Brain Res. 2007;1141:228-234. doi:10.1016/j.brainres.2007.01.009

29. Song L, Ge S, Pachter JS. Caveolin-1 regulates expression of junction-associated proteins in brain microvascular endothelial cells. Blood. 2007;109:1515-1523. doi:10.1182/blood-2006-07-034009

30. Kigerl KA, Vaccari J, Dietrich WD, et al. Pattern recognition receptors and central nervous system repair. Exp Neurol. 2014;258:5-16. doi:10.1016/j.expneurol.2014.01.001

31. Amarante-Mendes GP, Adjemian S, Branco LM, et al. Pattern recognition receptors and the host cell death molecular machinery. Front Immunol. 2018;9:2379. doi:10.3389/fimmu.2018.02379

32. David BT, Ratnayake A, Amarante MA, et al. A toll-like receptor 9 antagonist reduces pain hypersensitivity and the inflammatory response in spinal cord injury. Neurobiol Dis. 2013;54:194-205. doi:10.1016/j.nbd.2012.12.012

33. Kigerl KA, Lai W, Rivest S, et al. Toll-like receptor (TLR)-2 and TLR-4 regulate inflammation, gliosis, and myelin sparing after spinal cord injury. $J$ Neurochem. 2007;102:37-50. doi:10.1111/ j.1471-4159.2007.04524.x

34. Vaccari J, Minkiewicz J, Wang X, et al. Astrogliosis involves activation of retinoic acid-inducible gene-like signaling in the innate immune response after spinal cord injury. Glia. 2012;60:414-421. doi:10.1002/glia.22275

35. Orr MB, Gensel JC. Spinal cord injury scarring and inflammation: therapies targeting glial and inflammatory responses. Neurotherapeutics. 2018;15:541-553. doi:10.1007/s13311-0180631-6 
36. Paolicelli RC, Bolasco G, Pagani F, et al. Synaptic pruning by microglia is necessary for normal brain development. Science. 2011;333:1456-1458. doi:10.1126/science.1202529

37. Ueno M, Fujita Y, Tanaka T, et al. Layer V cortical neurons require microglial support for survival during postnatal development. Nat Neurosci. 2013;16:543-551. doi:10.1038/nn.3358

38. Hagemeyer N, Hanft K-M, Akriditou M-A, et al. Microglia contribute to normal myelinogenesis and to oligodendrocyte progenitor maintenance during adulthood. Acta Neuropathol. 2017;134:441-458. doi:10.1007/s00401-017-1747-1

39. Hanke ML, Kielian T. Toll-like receptors in health and disease in the brain: mechanisms and therapeutic potential. Clin Sci 2011;121:367-387. doi:10.1042/CS20110164

40. Gaudet AD, Fonken LK. Glial cells shape pathology and repair after spinal cord injury. Neurotherapeutics. 2018;15:554-577. doi:10.1007/s13311-018-0630-7

41. Beck KD, Nguyen HX, Galvan MD, et al. Quantitative analysis of cellular inflammation after traumatic spinal cord injury: evidence for a multiphasic inflammatory response in the acute to chronic environment. Brain. 2010;133:433-447. doi:10.1093/ brain/awp322

42. Kigerl KA, Gensel JC, Ankeny DP, et al. Identification of two distinct macrophage subsets with divergent effects causing either neurotoxicity or regeneration in the injured mouse spinal cord. $J$ Neurosci. 2009;29:13435-13444. doi:10.1523/JNEUROSCI. 3257-09.2009

43. Hu X, Leak RK, Shi Y, et al. Microglial and macrophage polarization-new prospects for brain repair. Nat Rev Neurol. 2015;11:56-64. doi:10.1038/nrneurol.2014.207

44. Gensel JC, Zhang B. Macrophage activation and its role in repair and pathology after spinal cord injury. Brain Res. 2015;1619:111. doi:10.1016/j.brainres.2014.12.045

45. Halassa MM, Fellin T, Takano H, et al. Synaptic islands defined by the territory of a single astrocyte. J Neurosci. 2007;27:64736477. doi:10.1523/JNEUROSCI.1419-07.2007

46. Gómez-Gonzalo M, Martin-Fernandez M, Martínez-Murillo R, et al. Neuron-astrocyte signaling is preserved in the aging brain. Glia. 2017;65:569-580. doi:10.1002/glia.23112

47. Stogsdill JA, Ramirez J, Liu D, et al. Astrocytic neuroligins control astrocyte morphogenesis and synaptogenesis. Nature. 2017;551:192-197. doi:10.1038/nature24638

48. Liebner S, Dijkhuizen RM, Reiss Y, et al. Functional morphology of the blood-brain barrier in health and disease. Acta Neuropathol. 2018;135:311-336. doi:10.1007/s00401-018-1815-1

49. Attwell D, Buchan AM, Charpak S, et al. Glial and neuronal control of brain blood flow. Nature. 2010;468:232-243. doi:10.1038/nature09613

50. Bélanger M, Allaman I, Magistretti PJ. Brain energy metabolism: focus on astrocyte-neuron metabolic cooperation. Cell Metab. 2011;14:724-738. doi:10.1016/j.cmet.2011.08.016

51. Jensen CJ, Massie A, Keyser JD. Immune players in the CNS: the astrocyte. J Neuroimmune Pharmacol. 2013;8:824-839. doi:10.1007/s11481-013-9480-6

52. Li L, Acioglu C, Heary RF, et al. Role of astroglial toll-like receptors (TLRs) in central nervous system infections, injury and neurodegenerative diseases. Brain Behav Immun. 2021;91:740-755. doi:10.1016/j.bbi.2020.10.007

53. Rivieccio MA, Suh H-S, Zhao Y, et al. TLR3 ligation activates an antiviral response in human fetal astrocytes: a role for viperin/ cig5. J Immunol. 2006;177:4735-4741. doi:10.4049/ jimmunol.177.7.4735

54. Karimi-Abdolrezaee S, Billakanti R. Reactive astrogliosis after spinal cord injury-beneficial and detrimental effects. Mol Neurobiol. 2012;46:251-264. doi:10.1007/s12035-0128287-4
55. Almutairi MMA, Gong $\mathrm{C}, \mathrm{Xu} \mathrm{YG}$, et al. Factors controlling permeability of the blood-brain barrier. Cell Mol Life Sci. 2016;73:57-77. doi:10.1007/s00018-015-2050-8

56. Engelhardt B, Ransohoff RM. Capture, crawl, cross: the T cell code to breach the blood-brain barriers. Trends Immunol. 2012;33:579-589. doi:10.1016/j.it.2012.07.004

57. Gorina R, Font-Nieves M, Márquez-Kisinousky L, et al. Astrocyte TLR4 activation induces a proinflammatory environment through the interplay between MyD88-dependent NFkB signaling, MAPK, and Jak1/Stat1 pathways. Glia. 2011;59:242255. doi:10.1002/glia.21094

58. McKimmie CS, Graham GJ. Astrocytes modulate the chemokine network in a pathogen-specific manner. Biochem Biophys Res Commun. 2010;394:1006-1011. doi:10.1016/j.bbrc.2010. 03.111

59. Pedrazzi M, Patrone M, Passalacqua M, et al. Selective proinflammatory activation of astrocytes by high-mobility group box 1 protein signaling. J Immunol. 2007;179:8525-8532. doi:10.4049/ jimmunol.179.12.8525

60. Moreno M, Guo F, Ko EM, et al. Origins and significance of astrogliosis in the multiple sclerosis model, MOG peptide EAE. $J$ Neurol Sci. 2013;333:55-59. doi:10.1016/j.jns.2012.12.014

61. Dong Y, Benveniste EN. Immune function of astrocytes. Glia. 2001;36:180-190. doi:10.1002/glia.1107

62. Rostami J, Fotaki G, Sirois J, et al. Astrocytes have the capacity to act as antigen-presenting cells in the Parkinson's disease brain. $J$ Neuroinflammation. 2020;17:119. doi:10.1186/s12974-02001776-7

63. Zamanian JL, Xu L, Foo LC, et al. Genomic analysis of reactive astrogliosis. $J$ Neurosci. 2012;32:6391-6410. doi:10.1523/ JNEUROSCI.6221-11.2012

64. Tarassishin L, Suh H-S, Lee SC. LPS and IL-1 differentially activate mouse and human astrocytes: role of CD14. Glia. 2014;62:999-1013. doi:10.1002/glia.22657

65. Maupu C, Enderlin J, Igert A, et al. Diisopropylfluorophosphateinduced status epilepticus drives complex glial cell phenotypes in adult male mice. Neurobiol Dis. 2021;152:105276. doi:10.1016/j. nbd.2021.105276

66. Giovannoni F, Quintana FJ. The role of astrocytes in CNS inflammation. Trends Immunol. 2020;41:805-819. doi:10.1016/j. it.2020.07.007

67. Yan Y, Ding X, Li K, et al. CNS-specific therapy for ongoing EAE by silencing IL-17 pathway in astrocytes. Mol Ther. 2012;20:1338-1348. doi:10.1038/mt.2012.12

68. Su Y, Chen Z, Du H, et al. Silencing miR-21 induces polarization of astrocytes to the A2 phenotype and improves the formation of synapses by targeting glypican 6 via the signal transducer and activator of transcription-3 pathway after acute ischemic spinal cord injury. FASEB J. 2019;33:10859-10871. doi:10.1096/ fj.201900743R

69. Zhao N, Xu X, Jiang Y, et al. Lipocalin-2 may produce damaging effect after cerebral ischemia by inducing astrocytes classical activation. J Neuroinflammation. 2019;16:168. doi:10.1186/ s12974-019-1556-7

70. Karababa A, Groos-Sahr K, Albrecht U, et al. Ammonia attenuates LPS-induced upregulation of pro-inflammatory cytokine mRNA in co-cultured astrocytes and microglia. Neurochem Res. 2017;42:737-749. doi:10.1007/s11064-016-2060-4

71. Liddelow SA, Guttenplan KA, Clarke LE, et al. Neurotoxic reactive astrocytes are induced by activated microglia. Nature. 2017;541:481-487. doi:10.1038/nature21029

72. Lepore AC, O'Donnell J, Kim AS, et al. Reduction in expression of the astrocyte glutamate transporter, GLT1, worsens functional and histological outcomes following traumatic spinal cord injury. Glia. 2011;59:1996-2005. doi:10.1002/glia.21241 
73. Bezzi P, Domercq M, Brambilla L, et al. CXCR4-activated astrocyte glutamate release via TNFalpha: amplification by microglia triggers neurotoxicity. Nat Neurosci. 2001;4:702-710. doi:10.1038/89490

74. Norden DM, Fenn AM, Dugan A, et al. TGF $\beta$ produced by IL-10 redirected astrocytes attenuates microglial activation. Glia. 2014;62:881-895. doi:10.1002/glia.22647

75. Steelman AJ, Li J. Astrocyte galectin-9 potentiates microglial TNF secretion. J Neuroinflammation. 2014;11:144. doi:10.1186/ s12974-014-0144-0

76. Peterson SL, Nguyen HX, Mendez OA, et al. Complement protein C3 suppresses axon growth and promotes neuron loss. Sci Rep. 2017;7:12904. doi:10.1038/s41598-017-11410-x

77. Lian H, Litvinchuk A, Chiang -AC-A, et al. Astrocyte-microglia cross talk through complement activation modulates amyloid pathology in mouse models of Alzheimer's disease. J Neurosci. 2016;36:577-589. doi:10.1523/JNEUROSCI.2117-15.2016

78. Hung -C-C, Lin C-H, Chang H, et al. Astrocytic GAP43 induced by the TLR4/NF- $\kappa \mathrm{B} / \mathrm{STAT} 3$ axis attenuates astrogliosis-mediated microglial activation and neurotoxicity. $J$ Neurosci. 2016;36:2027-2043. doi:10.1523/JNEUROSCI.3457-15.2016

79. Acevedo G, Padala NK, Ni L, et al. Astrocytes inhibit microglial surface expression of dendritic cell-related co-stimulatory molecules through a contact-mediated process. $J$ Neurochem. 2013;125:575-587. doi:10.1111/jnc.12221

80. Zhou R, Gao J, Xiang C, et al. Salvianolic acid A attenuated myocardial infarction-induced apoptosis and inflammation by activating Trx. Naunyn Schmiedebergs Arch Pharmacol. 2020;393:991-1002. doi:10.1007/s00210-019-01766-4

81. Liu C-D, Liu -N-N, Zhang S, et al. Salvianolic acid A prevented cerebrovascular endothelial injury caused by acute ischemic stroke through inhibiting the Src signaling pathway. Acta Pharmacol Sin. 2021;42:370-381. doi:10.1038/s41401-02000568-2

82. Zhu J, Wang $\mathrm{R}, \mathrm{Xu}$ T, et al. Salvianolic acid A attenuates endoplasmic reticulum stress and protects against cholestasis-induced liver fibrosis via the SIRT1/HSF1 pathway. Front Pharmacol. 2018;9:1277. doi:10.3389/fphar.2018.01277

83. Zhou A-M, Xiang Y-J, Liu E-Q, et al. Salvianolic acid a inhibits platelet activation and aggregation in patients with type 2 diabetes mellitus. BMC Cardiovasc Disord. 2020;20:15. doi:10.1186/ s12872-019-01316-z

84. Yu D-S, Wang Y-S, Bi Y-L, et al. Salvianolic acid A ameliorates the integrity of blood-spinal cord barrier via miR-101/Cul3/Nrf2/ HO-1 signaling pathway. Brain Res. 2017;1657:279-287. doi:10.1016/j.brainres.2016.12.007

85. Wu Y, Xu S, Tian XY. The effect of salvianolic acid on vascular protection and possible mechanisms. Oxid Med Cell Longev. 2020;2020:5472096. doi:10.1155/2020/5472096

86. Li Z-M, Xu S-W, Liu P-Q. Salvia miltiorrhizaBurge (Danshen): a golden herbal medicine in cardiovascular therapeutics. Acta Pharmacol Sin. 2018;39:802-824. doi:10.1038/aps.2017.193

87. Fan Z-K, Lv G, Wang Y-F, et al. The protective effect of salvianolic acid B on blood-spinal cord barrier after compression spinal cord injury in rats. $J$ Mol Neurosci. 2013;51:986-993. doi:10.1007/s12031-013-0083-8

88. Fu J, Fan H-B, Guo Z, et al. Salvianolic acid B attenuates spinal cord ischemia-reperfusion-induced neuronal injury and oxidative stress by activating the extracellular signal-regulated kinase pathway in rats. J Surg Res. 2014;188:222-230. doi:10.1016/j. jss.2013.11.1118

89. Krzysztoforska K, Mirowska-Guzel D, Widy-Tyszkiewicz E. Pharmacological effects of protocatechuic acid and its therapeutic potential in neurodegenerative diseases: review on the basis of in vitro and in vivo studies in rodents and humans. Nutr Neurosci. 2019;22:72-82. doi:10.1080/1028415X.2017.1354543
90. Park CS, Lee JY, Choi HY, et al. Protocatechuic acid improves functional recovery after spinal cord injury by attenuating bloodspinal cord barrier disruption and hemorrhage in rats. Neurochem Int. 2019;124:181-192. doi:10.1016/j.neuint.2019.01.013

91. Hu J-Z, Huang J-H, Xiao Z-M, et al. Tetramethylpyrazine accelerates the function recovery of traumatic spinal cord in rat model by attenuating inflammation. J Neurol Sci. 2013;324:94-99. doi:10.1016/j.jns.2012.10.009

92. Wang C, Wang P, Zeng W, et al. Tetramethylpyrazine improves the recovery of spinal cord injury via Akt/Nrf2/HO-1 pathway. Bioorg Med Chem Lett. 2016;26:1287-1291. doi:10.1016/j. bmcl.2016.01.015

93. Fan L, Wang K, Shi Z, et al. Tetramethylpyrazine protects spinal cord and reduces inflammation in a rat model of spinal cord ischemia-reperfusion injury. J Vasc Surg. 2011;54:192-200. doi:10.1016/j.jvs.2010.12.030

94. Shin J-W, Moon J-Y, Seong J-W, et al. Effects of tetramethylpyrazine on microglia activation in spinal cord compression injury of mice. Am J Chin Med. 2013;41:1361-1376. doi:10.1142/ S0192415X13500912

95. Zhang L, Lu X, Gong L, et al. Tetramethylpyrazine protects blood-spinal cord barrier integrity by modulating microglia polarization through activation of STAT3/SOCS3 and inhibition of NFкВ signaling pathways in experimental autoimmune encephalomyelitis mice. Cell Mol Neurobiol. 2021;41:717-731. doi:10.1007/s10571-020-00878-3

96. Du Q-H, Peng C, Zhang H. Polydatin: a review of pharmacology and pharmacokinetics. Pharm Biol. 2013;51:1347-1354. doi:10.3109/13880209.2013.792849

97. Lv R, Du L, Liu X, et al. Polydatin alleviates traumatic spinal cord injury by reducing microglial inflammation via regulation of iNOS and NLRP3 inflammasome pathway. Int Immunopharmacol. 2019;70:28-36. doi:10.1016/j.intimp.2019. 02.006

98. Zhou Y-X, Gong X-H, Zhang H, et al. A review on the pharmacokinetics of paeoniflorin and its anti-inflammatory and immunomodulatory effects. Biomed Pharmacother. 2020;130:110505. doi:10.1016/j.biopha.2020.110505

99. Wang B, Dai W, Shi L, et al. Neuroprotection by paeoniflorin against nuclear factor kappa B-induced neuroinflammation on spinal cord injury. Biomed Res Int. 2018;2018:9865403. doi:10.1155/2018/9865403

100. Liu P, Cheng J, Ma S, et al. Paeoniflorin attenuates chronic constriction injury-induced neuropathic pain by suppressing spinal NLRP3 inflammasome activation. Inflammopharmacology. 2020;28:14951508. doi:10.1007/s10787-020-00737-z

101. Meeran MFN, Goyal SN, Suchal K, et al. Pharmacological properties, molecular mechanisms, and pharmaceutical development of asiatic acid: a pentacyclic triterpenoid of therapeutic promise. Front Pharmacol. 2018;9:892.

102. Gurcan O, Gurcay AG, Kazanci A, et al. Effect of asiatic acid on the treatment of spinal cord injury: an experimental study in rats. Turk Neurosurg. 2017;27:259-264. doi:10.5137/1019-5149. JTN.15747-15.2

103. Jiang W, Li M, He F, et al. Neuroprotective effect of asiatic acid against spinal cord injury in rats. Life Sci. 2016;157:45-51. doi:10.1016/j.1fs.2016.05.004

104. Rocha J, Eduardo-Figueira M, Barateiro A, et al. Anti-inflammatory effect of rosmarinic acid and an extract of Rosmarinus officinalis in rat models of local and systemic inflammation. Basic Clin Pharmacol Toxicol. 2015;116:398-413. doi:10.1111/ bcpt.12335

105. Shang A-J, Yang Y, Wang H-Y, et al. Spinal cord injury effectively ameliorated by neuroprotective effects of rosmarinic acid. Nutr Neurosci. 2017;20:172-179. doi:10.1080/1028415X.2015. 1103460 
106. Ma Z, Lu Y, Yang F, et al. Rosmarinic acid exerts a neuroprotective effect on spinal cord injury by suppressing oxidative stress and inflammation via modulating the Nrf2/HO-1 and TLR4/NFкB pathways. Toxicol Appl Pharmacol. 2020;397:115014. doi:10.1016/j.taap.2020.115014

107. Zhou Y-X, Zhang H, Peng C. Puerarin: a review of pharmacological effects. Phytother Res. 2014;28:961-975. doi:10.1002/ ptr.5083

108. Zhang D, Ma G, Hou M, et al. The neuroprotective effect of puerarin in acute spinal cord injury rats. Cell Physiol Biochem. 2016;39:1152-1164. doi:10.1159/000447822

109. Liu M, Liao K, Yu C, et al. Puerarin alleviates neuropathic pain by inhibiting neuroinflammation in spinal cord. Mediators Inflamm. 2014;2014:485927. doi:10.1155/2014/485927

110. Li N, Ou J, Bao N, et al. Design, synthesis and biological evaluation of novel plumbagin derivatives as potent antitumor agents with STAT3 inhibition. Bioorg Chem. 2020;104:104208. doi:10.1016/j.bioorg.2020.104208

111. Zhang W, Cheng L, Hou Y, et al. Plumbagin protects against spinal cord injury-induced oxidative stress and inflammation in Wistar rats through Nrf-2 upregulation. Drug Res. 2015;65:495499. doi:10.1055/s-0034-1389950

112. Yang W, Yang Y, Yang J-Y, et al. Treatment with bone marrow mesenchymal stem cells combined with plumbagin alleviates spinal cord injury by affecting oxidative stress, inflammation, apoptosis and the activation of the Nrf2 pathway. Int $\mathrm{J} \mathrm{Mol}$ Med. 2016;37:1075-1082. doi:10.3892/ijmm.2016.2498

113. Wang S, Ren D. Allicin protects traumatic spinal cord injury through regulating the HSP70/Akt/iNOS pathway in mice. $\mathrm{Mol}$ Med Rep. 2016;14:3086-3092. doi:10.3892/mmr.2016.5651

114. Lv R, Mao N, Wu J, et al. Neuroprotective effect of allicin in a rat model of acute spinal cord injury. Life Sci. 2015;143:114-123. doi:10.1016/j.1fs.2015.11.001

115. Liu S-G, Ren P-Y, Wang G-Y, et al. Allicin protects spinal cord neurons from glutamate-induced oxidative stress through regulating the heat shock protein 70/inducible nitric oxide synthase pathway. Food Funct. 2015;6:321-330. doi:10.1039/c4fo00761a

116. Vincenzo AD, Tana C, Hadi HE, et al. Antioxidant, antiInflammatory, and metabolic properties of tocopherols and tocotrienols: clinical implications for vitamin E supplementation in diabetic kidney disease. Int $J$ Mol Sci. 2019;20:5101. doi:10.3390/ijms20205101

117. Ghanem P, Zouein A, Mohamad M, et al. The vitamin E derivative gamma tocotrienol promotes anti-tumor effects in acute myeloid leukemia cell lines. Nutrients. 2019;11:2808. doi:10.3390/ nu11112808

118. Frank J, Chin XWD, Schrader C, et al. Do tocotrienols have potential as neuroprotective dietary factors? Ageing Res Rev. 2012;11:163-180. doi:10.1016/j.arr.2011.06.006

119. Xun C, Mamat M, Guo H, et al. Tocotrienol alleviates inflammation and oxidative stress in a rat model of spinal cord injury via suppression of transforming growth factor- $\beta$. Exp Ther Med. 2017;14:431-438. doi:10.3892/etm.2017.4505

120. Ho Y, Lin Y-S, Liu H-L, et al. Biological mechanisms by which antiproliferative actions of resveratrol are minimized. Nutrients. 2017;9:1046. doi:10.3390/nu9101046

121. Xia N, Daiber A, Förstermann U, et al. Antioxidant effects of resveratrol in the cardiovascular system. $\mathrm{Br} J$ Pharmacol. 2017;174:1633-1646. doi:10.1111/bph.13492

122. Xu D, Li Y, Zhang B, et al. Resveratrol alleviate hypoxic pulmonary hypertension via anti-inflammation and anti-oxidant pathways in rats. Int $J$ Med Sci. 2016;13:942-954. doi:10.7150/ ijms. 16810

123. Liu C, Shi Z, Fan L, et al. Resveratrol improves neuron protection and functional recovery in rat model of spinal cord injury. Brain Res. 2011;1374:100-109. doi:10.1016/j.brainres.2010.11.061
124. Fan R, Zhang Y, Botchway BOA, et al. Resveratrol can attenuate astrocyte activation to treat spinal cord injury by inhibiting inflammatory responses. Mol Neurobiol. 2021;19:1-15. doi:10.1007/s12035-021-02509-4

125. Zhao H, Chen S, Gao K, et al. Resveratrol protects against spinal cord injury by activating autophagy and inhibiting apoptosis mediated by the SIRT1/AMPK signaling pathway. Neuroscience. 2017;348:241-254. doi:10.1016/j. neuroscience.2017.02.027

126. $\mathrm{Xu} \mathrm{L}$, Botchway BOA, Zhang $\mathrm{S}$, et al. Inhibition of $\mathrm{NF}-\kappa \mathrm{B}$ signaling pathway by resveratrol improves spinal cord injury. Front Neurosci. 2018;12. doi:10.3389/fnins.2018.00690

127. Ge R, Zhu Y, Diao Y, et al. Anti-edema effect of epigallocatechin gallate on spinal cord injury in rats. Brain Res. 2013;1527:40-46. doi:10.1016/j.brainres.2013.06.009

128. Urdzikova LM, Ruzicka J, Karova K, et al. A green tea polyphenol epigallocatechin-3-gallate enhances neuroregeneration after spinal cord injury by altering levels of inflammatory cytokines. Neuropharmacology. 2017;126:213-223. doi:10.1016/j. neuropharm.2017.09.006

129. Liu L, Zhang W, Wang L, et al. Curcumin prevents cerebral ischemia reperfusion injury via increase of mitochondrial biogenesis. Neurochem Res. 2014;39:1322-1331. doi:10.1007/s11064014-1315-1

130. Samini F, Samarghandian S, Borji A, et al. Curcumin pretreatment attenuates brain lesion size and improves neurological function following traumatic brain injury in the rat. Pharmacol Biochem Behav. 2013;110:238-244. doi:10.1016/j. pbb.2013.07.019

131. Yu D-S, Cao Y, Mei X-F, et al. Curcumin improves the integrity of blood-spinal cord barrier after compressive spinal cord injury in rats. $J$ Neurol Sci. 2014;346:51-59. doi:10.1016/j. jns.2014.07.056

132. Daverey A, Agrawal SK. Curcumin protects against white matter injury through $\mathrm{NF}-\kappa \mathrm{B}$ and $\mathrm{Nrf} 2$ cross talk. J Neurotrauma. 2020;37:1255-1265. doi:10.1089/neu.2019.6749

133. Yuan J, Zou M, Xiang X, et al. Curcumin improves neural function after spinal cord injury by the joint inhibition of the intracellular and extracellular components of glial scar. J Surg Res. 2015;195:235-245. doi:10.1016/j.jss.2014.12.055

134. Gao F, Shen J, Zhao L, et al. Curcumin alleviates lipopolysaccharide (LPS)-activated neuroinflammation via modulation of miR-199b-5p/IkB kinase $\beta$ (IKKb)/nuclear factor kappa B (NF$\kappa \mathrm{B})$ pathway in microglia. Med Sci Monit. 2019;25:9801-9810. doi:10.12659/MSM.918237

135. Barboza JN, Filho C, Silva RO, et al. An overview on the antiinflammatory potential and antioxidant profile of eugenol. Oxid Med Cell Longev. 2018;2018:3957262. doi:10.1155/2018/ 3957262

136. Ma L, Mu Y, Zhang Z, et al. Eugenol promotes functional recovery and alleviates inflammation, oxidative stress, and neural apoptosis in a rat model of spinal cord injury. Restor Neurol Neurosci. 2018;36:659-668.

137. Liu Y, Gao J, Peng M, et al. A review on central nervous system effects of gastrodin. Front Pharmacol. 2018;9:24. doi:10.3389/ fphar.2018.00024

138. Du F, Wang X, Shang B, et al. Gastrodin ameliorates spinal cord injury via antioxidant and anti-inflammatory effects. Acta Biochim Pol. 2016;63:589-593. doi:10.18388/abp.2016_1272

139. $\mathrm{Hu} \mathrm{J}-\mathrm{Z}$, Wang $\mathrm{X}-\mathrm{K}$, Cao $\mathrm{Y}$, et al. Potentiation of spinal cord conduction and neuroprotection following nanodelivery of DL3-n-butylphthalide in titanium implanted nanomaterial in a focal spinal cord injury induced functional outcome, blood-spinal cord barrier breakdown and edema formation. Int Rev Neurobiol. 2019;146:153-188. doi:10.1016/bs.irn.2019.06.009 
140. Zheng B, Zhou Y, Zhang H, et al. Dl-3-n-butylphthalide prevents the disruption of blood-spinal cord barrier via inhibiting endoplasmic reticulum stress following spinal cord injury. Int J Biol Sci. 2017;13:1520-1531. doi:10.7150/ijbs.21107

141. Ye Z-Y, Xing H-Y, Wang B, et al. DL-3-n-butylphthalide protects the blood-brain barrier against ischemia/hypoxia injury via upregulation of tight junction proteins. Chin Med J. 2019;132:1344-1353. doi:10.1097/CM9.0000000000 000232

142. He Z, Zhou Y, Lin L, et al. Dl-3-n-butylphthalide attenuates acute inflammatory activation in rats with spinal cord injury by inhibit-

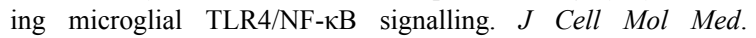
2017;21:3010-3022. doi:10.1111/jcmm.13212

143. Sowndhararajan K, Deepa P, Kim M, et al. Neuroprotective and cognitive enhancement potentials of baicalin: a review. Brain Sci. 2018;8:104. doi:10.3390/brainsci8060104

144. Cao Y, Lia G, Wang Y-F, et al. Neuroprotective effect of baicalin on compression spinal cord injury in rats. Brain Res. 2010;1357:115-123. doi:10.1016/j.brainres.2010.07.108

145. Tu X-K, Yang W-Z, Liang R-S, et al. Effect of baicalin on matrix metalloproteinase- 9 expression and blood-brain barrier permeability following focal cerebral ischemia in rats. Neurochem Res. 2011;36:2022-2028. doi:10.1007/s11064-011-0526-y

146. Zhu H, Wang Z, Xing Y, et al. Baicalin reduces the permeability of the blood-brain barrier during hypoxia in vitro by increasing the expression of tight junction proteins in brain microvascular endothelial cells. $J$ Ethnopharmacol. 2012;141:714-720. doi:10.1016/j.jep.2011.08.063

147. Kang S, Liu S, Li H, et al. Baicalin effects on rats with spinal cord injury by anti-inflammatory and regulating the serum metabolic disorder. $J$ Cell Biochem. 2018;119:7767-7779. doi: $10.1002 /$ jcb. 27136

148. Li L, Hou X, Xu R, et al. Research review on the pharmacological effects of astragaloside IV. Fundam Clin Pharmacol. 2017;31:1736. doi:10.1111/fcp. 12232

149. Lin J, Pan X, Huang C, et al. Dual regulation of microglia and neurons by Astragaloside IV-mediated mTORC1 suppression promotes functional recovery after acute spinal cord injury. $J$ Cell Mol Med. 2020;24:671-685. doi:10.1111/jcmm.14776

150. Zhang D, Wang Q, Wang S, et al. Astragoloside IV loaded polycaprolactone membrane repairs blood spinal cord barrier and recovers spinal cord function in traumatic spinal cord injury. $J$ Biomed Nanotechnol. 2019;15:799-812. doi:10.1166/ jbn.2019.2715

151. Dai W-L, Zhang L, Han L, et al. Regulation of the K ATP-JNK gap junction signaling pathway by immunomodulator astragaloside IV attenuates neuropathic pain. Reg Anesth Pain Med. 2020;45:955-963. doi:10.1136/rapm-2020-101411

152. Pollier J, Goossens A. Oleanolic acid. Phytochemistry. 2012;77:10-15. doi:10.1016/j.phytochem.2011.12.022

153. Martín R, Carvalho-Tavares J, Hernández M, et al. Beneficial actions of oleanolic acid in an experimental model of multiple sclerosis: a potential therapeutic role. Biochem Pharmacol. 2010;79:198-208. doi:10.1016/j.bcp.2009.08.002

154. Wang J-L, Ren C-H, Feng J, et al. Oleanolic acid inhibits mouse spinal cord injury through suppressing inflammation and apoptosis via the blockage of $\mathrm{p} 38$ and JNK MAPKs. Biomed Pharmacother. 2020;123:109752. doi:10.1016/j.biopha.201 9.109752

155. Chen D, Huang C, Chen Z. A review for the pharmacological effect of lycopene in central nervous system disorders. Biomed Pharmacother. 2019;111:791-801. doi:10.1016/j. biopha.2018.12.151

156. Zhang Q, Wang J, Gu Z, et al. Effect of lycopene on the bloodspinal cord barrier after spinal cord injury in mice. Biosci Trends. 2016;10:288-293. doi:10.5582/bst.2016.01062
157. Hua Y, Xu N, Ma T, et al. Anti-inflammatory effect of lycopene on experimental spinal cord ischemia injury via cyclooxygenase-2 suppression. Neuroimmunomodulation. 2019;26:84-92. doi: $10.1159 / 000495466$

158. Budzynska B, Faggio C, Kruk-Slomka M, et al. Rutin as neuroprotective agent: from bench to bedside. Curr Med Chem. 2019;26:5152-5164. doi:10.2174/0929867324666171003114154

159. Zhang P, Ma X. Effect of rutin on spinal cord injury through inhibition of the expression of MIP-2 and activation of MMP-9, and downregulation of Akt phosphorylation. Mol Med Rep. 2015;12:7554-7560. doi:10.3892/mmr.2015.4357

160. Wu J, Maoqiang L, Fan H, et al. Rutin attenuates neuroinflammation in spinal cord injury rats. $J$ Surg Res. 2016;203:331-337. doi:10.1016/j.jss.2016.02.041

161. Çiftçi U, Delen E, Vural M, et al. Efficiacy of resveratrol and quercetin after experimental spinal cord injury. Ulus Travma Acil Cerrahi Derg. 2016;22:423-431. doi:10.5505/tjtes.2016.44575

162. Schültke E, Griebel RW, Juurlink BHJ. Quercetin attenuates inflammatory processes after spinal cord injury in an animal model. Spinal Cord. 2010;48:857-861. doi:10.1038/sc.2010.45

163. Wang Y, Li W, Wang M, et al. Quercetin reduces neural tissue damage and promotes astrocyte activation after spinal cord injury in rats. J Cell Biochem. 2018;119:2298-2306. doi:10.1002/ jcb. 26392

164. Fan H, Tang H-B, Shan L-Q, et al. Quercetin prevents necroptosis of oligodendrocytes by inhibiting macrophages/microglia polarization to M1 phenotype after spinal cord injury in rats. $J$ Neuroinflammation. 2019;16:206. doi:10.1186/s12974-019$1613-2$

165. Jiang W, Huang Y, Han N, et al. Quercetin suppresses NLRP3 inflammasome activation and attenuates histopathology in a rat model of spinal cord injury. Spinal Cord. 2016;54:592-596. doi:10.1038/sc.2015.227

166. Zhang S, Liu Y, Zhao Z, et al. Effects of green tea polyphenols on caveolin-1 of microvessel fragments in rats with cerebral ischemia. Neurol Res. 2010;32:963-970. doi:10.1179/ 016164110X12700393823570

167. Liu X, Wang Z, Wang P, et al. Green tea polyphenols alleviate early BBB damage during experimental focal cerebral ischemia through regulating tight junctions and PKCalpha signaling. $B M C$ Complement Altern Med. 2013;13:187. doi:10.1186/1472-688213-187

168. Yu D-S, Liu L-B, Cao Y, et al. Combining bone marrow stromal cells with green tea polyphenols attenuates the blood-spinal cord barrier permeability in rats with compression spinal cord injury. $J$ Mol Neurosci. 2015;56:388-396. doi:10.1007/s12031-015-0564-z

169. Lee JY, Choi HY, Baik HH, et al. Cordycepin-enriched WIB$801 \mathrm{C}$ from Cordyceps militaris improves functional recovery by attenuating blood-spinal cord barrier disruption after spinal cord injury. $J$ Ethnopharmacol. 2017;203:90-100. doi:10.1016/j. jep.2017.03.047

170. Kang O-H, Lee G-H, Choi HJ, et al. Ethyl acetate extract from Angelica Dahuricae Radix inhibits lipopolysaccharide-induced production of nitric oxide, prostaglandin E2 and tumor necrosis factor-alpha via mitogen-activated protein kinases and nuclear factor-kappaB in macrophages. Pharmacol Res. 2007;55:263270. doi:10.1016/j.phrs.2006.12.001

171. Moon YJ, Lee JY, Oh MS, et al. Inhibition of inflammation and oxidative stress by Angelica dahuricae radix extract decreases apoptotic cell death and improves functional recovery after spinal cord injury. J Neurosci Res. 2012;90:243-256. doi:10.1002/ jnr.22734

172. Tian X, Liang T, Liu Y, et al. Extraction, structural characterization, and biological functions of Lycium Barbarum Polysaccharides: a review. Biomolecules. 2019;9:389. doi:10.3390/biom9090389 
173. Zhang Y-K, Wang J, Liu L, et al. The effect of Lycium barbarum on spinal cord injury, particularly its relationship with M1 and M2 macrophage in rats. BMC Complement Altern Med. 2013;13:67. doi:10.1186/1472-6882-13-67

174. Gillessen A, Schmidt HH-J. Silymarin as supportive treatment in liver diseases: a narrative review. Adv Ther. 2020;37:1279-1301. doi:10.1007/s12325-020-01251-y

175. Tsai M-J, Liao J-F, Lin D-Y, et al. Silymarin protects spinal cord and cortical cells against oxidative stress and lipopolysaccharide stimulation. Neurochem Int. 2010;57:867-875. doi:10.1016/j. neuint.2010.09.005
176. Yune TY, Lee JY, Cui CM, et al. Neuroprotective effect of Scutellaria baicalensis on spinal cord injury in rats. $J$ Neurochem. 2009;110:1276-1287. doi:10.1111/j.14714159.2009.06214.x

177. Tu T-H, Liou D-Y, Lin D-Y, et al. Characterizing the neuroprotective effects of S/B remedy (Scutellaria baicalensis Georgi and Bupleurum scorzonerifolfium Willd) in spinal cord injury. Molecules. 2019;24:1885. doi:10.3390/molecules24101885

\section{Publish your work in this journal}

The Journal of Inflammation Research is an international, peerreviewed open-access journal that welcomes laboratory and clinical findings on the molecular basis, cell biology and pharmacology of inflammation including original research, reviews, symposium reports, hypothesis formation and commentaries on: acute/chronic inflammation; mediators of inflammation; cellular processes; molecular mechanisms; pharmacology and novel anti-inflammatory drugs; clinical conditions involving inflammation. The manuscript management system is completely online and includes a very quick and fair peerreview system. Visit http://www.dovepress.com/testimonials.php to read real quotes from published authors.

Submit your manuscript here: https://www.dovepress.com/journal-of-inflammation-research-journal 